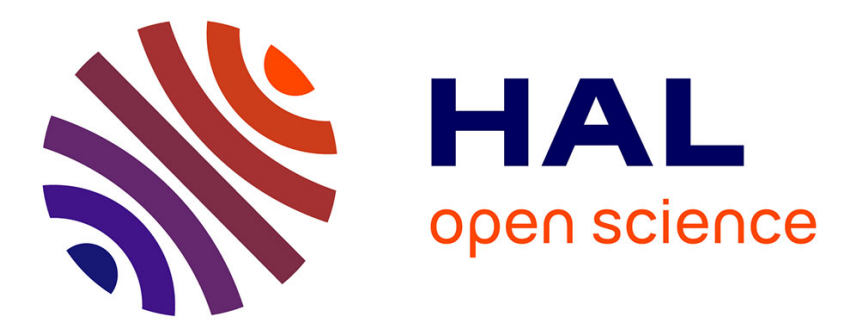

\title{
Equations of state for the thermodynamic properties of binary mixtures for helium-4, neon, and argon
}

Jakub Tkaczuk, Ian Bell, Eric W Lemmon, Nicolas Luchier, François Millet

\section{To cite this version:}

Jakub Tkaczuk, Ian Bell, Eric W Lemmon, Nicolas Luchier, François Millet. Equations of state for the thermodynamic properties of binary mixtures for helium-4, neon, and argon. Journal of Physical and Chemical Reference Data, 2020, 49, pp.023101. 10.1063/1.5142275 . hal-02893227

\section{HAL Id: hal-02893227 \\ https://hal.science/hal-02893227}

Submitted on 8 Jul 2020

HAL is a multi-disciplinary open access archive for the deposit and dissemination of scientific research documents, whether they are published or not. The documents may come from teaching and research institutions in France or abroad, or from public or private research centers.
L'archive ouverte pluridisciplinaire HAL, est destinée au dépôt et à la diffusion de documents scientifiques de niveau recherche, publiés ou non, émanant des établissements d'enseignement et de recherche français ou étrangers, des laboratoires publics ou privés. 


\title{
Equations of state for the thermodynamic properties of binary mixtures for helium-4, neon, and argon
}

\author{
Jakub Tkaczuk, ${ }^{1, \text { a) }}$ lan H. Bell, ${ }^{2, \text { b) }}$ Eric W. Lemmon, ${ }^{2, c)}$ Nicolas Luchier, ${ }^{1}$ and François Millet ${ }^{1}$ \\ 1) Université Grenoble Alpes, CEA IRIG-dSBT, F-38000 Grenoble, France \\ 2) National Institute of Standards and Technology, Boulder, Colorado 80305, United States \\ (Dated: 19 March 2020)
}

Based upon the conceptual design reports for the Future Circular Collider cryogenic system, the need for more accurate thermodynamic property models of cryogenic mixtures of noble gases was identified. Both academic institutes and industries have identified the lack of a reliable equation of state for mixtures used at very low temperatures. Detailed cryogenic architecture modeling and design cannot be carried out without accurate fluid properties. Therefore, the helium-neon equation was the first goal of this work and it was further extended to other fluids beneficial for scientific and industrial applications beyond the particle physics needs. The properties of the noble gas mixtures of helium-neon, neon-argon, and helium-argon are accurately modeled with the equations of state explicit in the Helmholtz energy.

Key words: helium-4; neon; argon; equation of state; fundamental equation; thermodynamic properties.

\section{CONTENTS}

1 Introduction ......................... 2

2 Fundamental equation of state .............. 2

2.1 Optimization algorithm ................ 3

2.2 Available data used for the equation of state development ......................... 3

2.3 Fluid properties scaling $\ldots \ldots \ldots \ldots \ldots \ldots \ldots \ldots$

3 Results ............................ 6

3.1 Uncertainty discussion for single-phase ....... 6

3.2 Uncertainty discussion at phase boundary....... 6

3.3 Ternary mixture $\ldots \ldots \ldots \ldots \ldots \ldots \ldots \ldots \ldots \ldots \ldots$

3.4 Validation data $\ldots \ldots \ldots \ldots \ldots \ldots \ldots \ldots \ldots \ldots \ldots$

4 Conclusions ........................ 11

5 Supplementary materials $\ldots \ldots \ldots \ldots \ldots \ldots \ldots \ldots . \ldots \ldots$

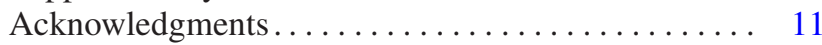

6 References .............................. 11

\section{LIST OF TABLES}

1 Molar mass and critical parameters for pure fluids.

2 Reducing temperature and density parameters ...

3 Available and used data for the development of the equations of state for ${ }^{4} \mathrm{He}-\mathrm{Ne} \ldots \ldots \ldots \ldots$.

4 Available and used data for the development of the equations of state for ${ }^{4} \mathrm{He}-\mathrm{Ar} \ldots \ldots \ldots \ldots$.

5 Available and used data for the development of the equations of state for $\mathrm{Ne}-\mathrm{Ar} \ldots \ldots \ldots \ldots .5$

6 Binary specific parameters obtained in this work . 6

7 Departure function coefficients ........... 8

8 Data points at equimolar $(0.5 / 0.5)$ composition for EOS validation $\ldots \ldots \ldots \ldots \ldots \ldots \ldots$

\section{2} 4

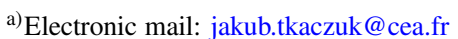

${ }^{b)}$ Electronic mail: ian.bell@nist.gov

${ }^{c)}$ Electronic mail: eric.lemmon@ nist.gov
}

\section{LIST OF FIGURES}

1 The phase envelopes for three binary mixtures shown in three-dimensional space of $p-T-x$ with isobars in red, and isotherms in black (a, c, e). Their projection on 2D plane of $p-x(\mathrm{~b}, \mathrm{~d}$, f) constructed with the algorithm for equilibria of binary mixtures ${ }^{62} \ldots \ldots \ldots \ldots \ldots \ldots \ldots$

2 Schematic representation of the orthogonal error calculations for the phase envelopes. Two experimental compositions for liquid and vapor from one measurement are marked with circles (the same pressure and temperature) and the respective isotherm evaluated with the EOS is plotted in two-dimensional space of reduced pressure $\hat{p}=p / p_{\mathrm{r}}$ and mole fraction in liquid $x$ and vapor $y$.

3 Relative deviations of the ${ }^{4} \mathrm{He}-\mathrm{Ne}$ equation to data........................ 9

4 Relative deviations of the ${ }^{4} \mathrm{He}-$ Ar equation to data 9

5 Relative deviations of the $\mathrm{Ne}-\mathrm{Ar}$ equation to data 9

6 Three mixture phase envelopes with color scales representing the absolute orthogonal error values plotted for $99.99 \%$ of data points for ${ }^{4} \mathrm{He}-\mathrm{Ne}$, $91.36 \%$ of data points for ${ }^{4} \mathrm{He}-\mathrm{Ar}$, and $99.23 \%$ of data points for $\mathrm{Ne}-\mathrm{Ar}$. The dotted line in each figure represents the reducing pressure scale from Eq. (11) ......................

7 Vapor-liquid and gas-gas equilibria orthogonal error values for three binary mixtures. Color intensity increases with increasing number of points in the hexagonal unitary area. The marginal histograms represent the number of data points in different data bins in whole pressure range (x-axis) and orthogonal error range (y-axis)

8 Cumulative percentage of points with error less than the specified value of the VLE orthogonal error for each EOS. ${ }^{4} \mathrm{He}-\mathrm{Ar}$ errors are considered for two pressure ranges: complete data availability pressure range and up to $100 \mathrm{MPa}$ with smaller orthogonal error $\ldots \ldots \ldots \ldots \ldots$

11

\section{8}

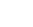

(1)

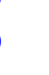




\section{INTRODUCTION}

The need for equations of state (EOS) capable of accurate representation of thermodynamic properties for cryogenic mixtures increases as more complex and more efficient cryogenic systems are being investigated and developed. Mixtures are presently considered as working fluids not only for large cryogenic systems but also for smaller, space-ready refrigerators. The potential applications of equations of state for noble gases include cooling cycles for fusion reactors or particle accelerators such as the Future Circular Collider, ${ }^{1}$ (FCC) space refrigerators, and modeling of welding processes with inert gases.

No accurate model has been developed so far for binary mixtures of helium-4, neon, and argon. $^{2}$ Until now, either linear or Lorentz-Berthelot ${ }^{3,4}$ classical rules for combining fluids have been used. ${ }^{5,6}$ Neither of them, however, represents quantum gas behavior correctly. ${ }^{7}$ Following the best practices from the domain of the equations of state, the quantum effects were included in the empirical model development with no special treatment.

The mixture models presented in this paper are explicit in the Helmholtz energy and use reducing parameters dependent on the mole fractions of mixture constituents and the critical parameters of the pure fluids. The Helmholtz energy $a$ is defined as follows

$$
a=u-T s,
$$

where $u$ is internal energy, $T$ is temperature and $s$ is entropy. Since it is a fundamental value, all other thermodynamic properties can be calculated from analytical derivatives. The Helmholtz energy formulation takes advantage of the consistent description of all fluid states because temperature and density are the independent variables. The pure fluid contributions, and the contribution from mixing for each binary mixture use an empirical formulation, which is temperature, density, and molar composition-dependent. The pure fluid contributions take advantage of the highly accurate EOS of pure fluids. In this work, each mixture-specific departure function consists of three exponential terms and four to five Gaussian terms. Comparisons to available experimental data are given to validate the accuracy of thermodynamic properties calculated with each equation of state.

The accuracy of mixture models is dependent on the pure fluid models. The equation of state for the considered mixture constituents, helium-4, neon, and argon have state-of-theart accuracy. This important starting point allows for the development of mixture models that will become the industrial standard. The critical parameters of the pure fluids, used in Helmholtz energy equations of state (HEOS) are presented in Table 1. Additionally, the equations, in the form presented in this paper, can be implemented in fluid property modeling software, such as REFPROP, ${ }^{8}$ CoolProp, ${ }^{9}$ or TREND. ${ }^{10}$
TABLE 1: Molar mass and critical parameters for pure fluids. ${ }^{a}$

\begin{tabular}{ccccc}
\hline \hline & $M /\left(\mathrm{kg} \mathrm{mol}^{-1}\right)$ & $T_{\mathrm{c}} / \mathrm{K}$ & $p_{\mathrm{c}} / \mathrm{MPa}$ & $\rho_{\mathrm{c}} /\left(\mathrm{mol} \mathrm{dm}^{-3}\right)$ \\
${ }^{4} \mathrm{He}^{11}$ & $4.0026 \times 10^{-3}$ & 5.195 & 0.22832 & 17.384 \\
$\mathrm{Ne}^{12}$ & $20.179 \times 10^{-3}$ & 44.400 & 2.66163 & 24.100 \\
$\mathrm{Ar}^{13}$ & $39.948 \times 10^{-3}$ & 150.687 & 4.86300 & 13.407 \\
\hline \hline
\end{tabular}

a The values have been truncated, for the full values see the fluid files in the supplementary materials.

TABLE 2: Reducing temperature and density parameters

\begin{tabular}{cccc}
\hline \hline$Y_{\mathrm{r}}$ & $Y_{\mathrm{c}, i}$ & $\beta_{Y, i j}$ & $Y_{i j}$ \\
\hline$T_{\mathrm{r}}$ & $T_{\mathrm{c}, i}$ & $\beta_{T, i j}$ & $\beta_{T, i j} \gamma_{T, i j}\left(T_{\mathrm{c}, i} T_{\mathrm{c}, j}\right)^{0.5}$ \\
$v_{\mathrm{r}}$ & $\frac{1}{\rho_{\mathrm{c}, i}}$ & $\beta_{v, i j}$ & $\beta_{v, i j} \gamma_{v, i j} \frac{1}{8}\left(\frac{1}{\rho_{\mathrm{c}, i}^{1 / 3}}+\frac{1}{\rho_{\mathrm{c}, j}^{1 / 3}}\right)^{3}$ \\
\hline \hline
\end{tabular}

\section{FUNDAMENTAL EQUATION OF STATE}

Among the available formulations of equations of state, the Helmholtz energy $a(T, \rho)$ has two important advantages. Unlike internal energy $u(v, s)$ and enthalpy $h(p, s)$, it is a function of measurable properties - temperature $T$ and density $\rho$. Moreover, unlike the Gibbs energy $g(T, p)$, it is continuous within the phase boundary, where $v$ is specific volume, $s$ is specific entropy, and $p$ is pressure.

The equation of state is used in a reduced form and is a function of non-dimensional quantities - reduced density and reciprocal reduced temperature ${ }^{14,15}$

$$
\tau=\frac{T_{\mathrm{r}}}{T} \quad \text { and } \quad \delta=\frac{\rho}{\rho_{\mathrm{r}}},
$$

where $T_{\mathrm{r}}$ and $\rho_{\mathrm{r}}$ are the reducing temperature and density. The most recent formulation ${ }^{15,16}$ allows for the use of a common form for reducing parameters for the mixture $\left(T_{\mathrm{r}}\right.$ and $\left.v_{\mathrm{r}}=1 / \rho_{\mathrm{r}}\right)$

$$
Y_{\mathrm{r}}(\bar{x})=\sum_{i=1}^{N} x_{i}^{2} Y_{\mathrm{c}, i}+\sum_{i=1}^{N} \sum_{j=i+1}^{N} 2 x_{i} x_{j} \frac{x_{i}+x_{j}}{\beta_{Y, i j}^{2} x_{i}+x_{j}} Y_{i j},
$$

where $Y$ is the parameter of interest, temperature $T$ or molar specific volume $v$ given in Table 2. $T_{\mathrm{c}, i}, \rho_{\mathrm{c}, i}$ are critical temperature and density of the pure constituents. $\beta_{T, i j}, \gamma_{T, i j}$, $\beta_{v, i j}$, and $\gamma_{v, i j}$ are the fitted parameters with both $\beta$ parameters being asymmetric, that is $\beta_{T, i j}=\beta_{T, j i}^{-1}$, and $\beta_{v, i j}=\beta_{v, j i}^{-1}$.

The total reduced Helmholtz energy $\alpha$ can be divided into an ideal gas part $\alpha^{\mathrm{o}}$ and a residual part $\alpha^{\mathrm{r}}$

$$
\alpha(\delta, \tau, \bar{x})=\frac{a(\rho, T, \bar{x})}{R T}=\alpha^{\mathrm{o}}(\rho, T, \bar{x})+\alpha^{\mathrm{r}}(\delta, \tau, \bar{x}),
$$

where $\bar{x}$ is the mole fraction vector, and $R$ is the mole fractionweighted average of the pure component values of the gas 
constant. The ideal and residual contributions represent the Helmholtz energy for the mixture. Both are functions of the pure fluid Helmholtz energies

$$
\begin{gathered}
\alpha^{\mathrm{o}}(\rho, T, \bar{x})=\sum_{i=1}^{N} x_{i}\left[\alpha_{\mathrm{o} i}^{\mathrm{o}}(\rho, T)+\ln x_{i}\right], \\
\alpha^{\mathrm{r}}(\delta, \tau, \bar{x})=\sum_{i=1}^{N} x_{i} \alpha_{\mathrm{o} i}^{\mathrm{r}}(\delta, \tau)+\sum_{i=1}^{N-1} \sum_{j=i+1}^{N} x_{i} x_{j} F_{i j} \alpha_{i j}^{\mathrm{r}}(\delta, \tau),
\end{gathered}
$$

where $x_{i}$ is the molar fraction of component $i, \alpha_{\mathrm{o} i}^{\mathrm{o}}$ is the pure fluid ideal Helmholtz energy, and $\alpha_{\mathrm{oi}}^{\mathrm{r}}$ is the pure fluid residual Helmholtz energy, both taken from the pure fluid EOS. $F_{i j}$ is the scaling parameter applied to the departure function, and here is set to unity because the departure functions have been fitted in this work for each binary mixture. $\alpha_{i j}^{\mathrm{r}}(\delta, \tau)$ is a pairwise departure function, dependent only on reduced variables $\delta$ and $\tau$.

The definition of the Helmholtz energy for mixtures allows to keep the pure fluid ideal $\alpha_{\mathrm{o} i}^{\mathrm{o}}$ and residual $\alpha_{\mathrm{o} i}^{\mathrm{r}}$ contributions unchanged as defined for the pure constituents. The mixture models presented in this paper are valid only with the pure fluid EOS used for their development. If new, and more accurate EOS for one of the constituents is developed, the equations for mixtures presented here may lose their validity and most probably must be refitted according to the updated pure fluid equations of state.

The last, previously undefined part of the Helmholtz energy for mixtures is the departure function, which depends on the reduced variables, and the adjustable parameters. Unlike in the GERG-2008 definition, ${ }^{15}$ the departure function used in this work is temperature dependent

$$
\begin{aligned}
\alpha_{i j}^{\mathrm{r}}(\delta, \tau) & =\sum_{k=1}^{8} n_{i j, k} \delta^{d_{i j, k}} \tau^{t_{i j, k}} \\
& \times \exp \left(-\eta_{i j, k}\left(\delta-\varepsilon_{i j, k}\right)^{2}-\beta_{i j, k}\left(\tau-\gamma_{i j, k}\right)^{2}\right),
\end{aligned}
$$

where $d_{i j, k}, n_{i j, k}, t_{i j, k}, \beta_{i j, k}, \gamma_{i j, k}, \varepsilon_{i j, k}$, and $\eta_{i j, k}$ are fitted parameters. Although they are empirical and arbitrary, constraints on their values were used during the fitting process in order to obtain physically correct EOS behavior (see Supplemental materials). The summation comprises the polynomial terms, and the Gaussian bell-shaped terms.

\subsection{Optimization algorithm}

The algorithm used for the equations of state development is based on non-linear regression analysis and the LevenbergMarquardt method. ${ }^{17,18}$ It was used to minimize the sum of squares of weighted data points, and constraints with applied limits on derivatives of the Helmholtz energy in Eq. (4). The expression for residual sum of squares is given as

$$
\mathrm{SSQ}=\sum_{i=1}^{N_{\rho}} W_{\rho, i} F_{\rho, i}^{2}+\sum_{i=1}^{N_{w}} W_{w, i} F_{w, i}^{2}+\sum_{i=1}^{N_{c_{\mathrm{V}}}} W_{c_{\mathrm{v}}, i} F_{c_{\mathrm{v}}, i}^{2}+\ldots
$$

where $W_{x}$ is the weight assigned to each data point of the thermodynamic property $x$, and $F_{x}$ is the function used to minimize the relative deviation between the data points and the equation of state. ${ }^{19}$ Deviations do not have to be evaluated as the sum of squares. During the fitting process, the method for calculating the contribution to the total sum of deviations was changed periodically to use the sum of squares, cubes, fourthor sixth-powers to find the best possible solution.

Phase equilibrium data is first fitted with the algorithm, and later, when satisfactory agreement between the data and the model is reached at the phase boundary, the single-phase data points are used to improve the model (e.g., $\rho p T$, speed of sound, etc.). The functional behavior is constantly constrained by applying weights on limits for the coefficients. All data points and applied constraints are provided in the supplemental materials.

The quality of the equation of state is determined through comparison of calculated deviations of data points and values from the equation of state. The errors for single-phase properties were evaluated numerically and deviations between the calculated values and available data points are discussed in section 33.1. The deviations at the phase equilibria, vaporliquid equilibrium (VLE) and gas-gas equilibrium (GGE) if it exists, were evaluated not only numerically but also visually by comparing the available data points with the isotherms calculated with the equation of state as shown in Fig. 1. A new approach, useful for the phase boundary uncertainty discussion, is presented in section 33.2.

\subsection{Available data used for the equation of state development}

The experimental data on thermophysical properties available in the literature were collected and are presented in Tables 3,4 , and 5 , along with the number of data points in every data set and the number of points used in the EOS development process. When the experimental points were omitted (available vs. used data points for single entry from literature), it is because of either incomplete information needed for the EOS development or questionable accuracy.

Average absolute deviations in Tables 3, 4, and 5 were calculated as follows

$$
\mathrm{AAD}=\frac{100}{N} \sum_{i}^{N}\left|\frac{x_{\mathrm{d}, i}-x_{\mathrm{EOS}, i}}{x_{\mathrm{d}, i}}\right|,
$$

where $x_{\mathrm{d}, i}$ is a data point, $x_{\mathrm{EOS}, i}$ is a respective value calculated from the equation of state, and $N$ is the number of points in data set. If the data set was not used in the fitting process, the AAD is printed in bold. 
TABLE 3: Available and used data for the development of the equations of state for ${ }^{4} \mathrm{He}-\mathrm{Ne}$

\begin{tabular}{|c|c|c|c|c|c|c|c|}
\hline \multirow[b]{2}{*}{ authors } & \multicolumn{2}{|c|}{ data points } & \multirow[b]{2}{*}{$T / \mathrm{K}$} & \multirow[b]{2}{*}{$p / \mathrm{MPa}$} & \multirow[b]{2}{*}{$x_{\mathrm{He}}$} & \multirow[b]{2}{*}{ author claimed uncertainty } & \multirow[b]{2}{*}{$\mathrm{AAD}^{\mathrm{a}} / \%$} \\
\hline & available & used & & & & & \\
\hline \multicolumn{8}{|c|}{ VLE data } \\
\hline Heck, Barrick ${ }^{20}$ & 76 & 36 & $27-42$ & $0.3-20$ & $0.01-0.36$ & $\pm 3 \%$ in $p$ & 15.0 \\
\hline Knorn $^{21}$ & 22 & 22 & $25-27$ & $0.6-5.1$ & $0.002-0.03$ & $\left\{\begin{array}{l} \pm 0.02 \mathrm{~K} \text { in } T \\
\pm 0.02 \% \text { in } x \\
\pm 0.1 \% \text { in } y\end{array}\right.$ & 4.3 \\
\hline & \multicolumn{7}{|c|}{$\rho p T$ data } \\
\hline Holborn, Otto ${ }^{22}$ & 39 & 39 & $273-673$ & $2.5-10$ & 0.28 & $\mathrm{~N} / \mathrm{A}^{\mathrm{b}}$ & 0.26 \\
\hline Kestin et $_{\text {al. }}{ }^{23}$ & 97 & 97 & 298 & $0.2-12.2$ & $0.23,0.80$ & $\pm 0.1 \%$ in $\rho$ & 0.20 \\
\hline Kestin, Nagashima ${ }^{24}$ & 90 & 73 & $293-303$ & $0.1-6.3$ & $0.26-0.95$ & $\pm 0.1 \%$ in $\rho$ & 0.24 \\
\hline Richardson, Leachman 25 & 8 & 6 & $32-41$ & $0.5-2.1$ & $0.02-0.03$ & $N / A^{b}$ & 2.0 \\
\hline Vogl, Hall ${ }^{26}$ & 51 & 51 & $233-313$ & $0.1-3.6$ & 0.49 & $\pm 0.04 \%$ in $Z^{\mathrm{c}}$ & 0.081 \\
\hline \multicolumn{8}{|c|}{ Speed of sound - $w$} \\
\hline \multicolumn{7}{|c|}{ Second virial coefficient - $B$} & 9.6 \\
\hline Berman et al. ${ }^{28}$ & 3 & 0 & $15-20$ & & & $\pm 5 \%$ in $B$ & 55.3 \\
\hline Brewer, Vaughn 29 & 8 & 0 & $148-323$ & & & $\pm 5 \%$ in $B$ & 3.9 \\
\hline Holborn, Otto 22 & 5 & 0 & $273-673$ & & & $\mathrm{~N} / \mathrm{A}^{\mathrm{b}}$ & 8.8 \\
\hline Iomtev et al. ${ }^{30}$ & 6 & 0 & $15-20$ & & & $\pm 6 \%$ in $B$ & 57.6 \\
\hline Knobler et al. ${ }^{31}$ & 1 & 0 & 90 & & & $\pm 3 \%$ in $B$ & 5.9 \\
\hline Vogl, Hall ${ }^{26}$ & 3 & 0 & $233-313$ & & & $\pm 4 \%$ in $B$ & 3.6 \\
\hline
\end{tabular}

TABLE 4: Available and used data for the development of the equations of state for ${ }^{4} \mathrm{He}-\mathrm{Ar}$

\begin{tabular}{|c|c|c|c|c|c|c|c|}
\hline \multirow[b]{2}{*}{ authors } & \multicolumn{2}{|c|}{ data points } & \multirow[b]{2}{*}{$T / \mathrm{K}$} & \multirow[b]{2}{*}{$p / \mathrm{MPa}$} & \multirow[b]{2}{*}{$x_{\mathrm{He}}$} & \multirow[b]{2}{*}{ author claimed uncertainty } & \multirow[b]{2}{*}{$\mathrm{AAD}^{\mathrm{a}} / \%$} \\
\hline & available & $\overline{\text { used }}$ & & & & & \\
\hline \multicolumn{8}{|c|}{ VLE / GGE data } \\
\hline Mullins $^{32}$ & 354 & 0 & $68-108$ & $2.0-12$ & $0.001-0.02$ & $\begin{array}{l} \pm 0.03 \mathrm{~K} \text { in } T \\
\pm 0.5 \% \text { in } p \\
\pm 2 \% \text { in } x \\
\pm 3 \% \text { in } y \\
\pm 0.03 \mathrm{~K} \text { in } T\end{array}$ & 24.0 \\
\hline Mullins $^{33}$ & 187 & 187 & $85-140$ & $0.5-12$ & $0.00006-0.02$ & $\begin{array}{l} \pm 0.5 \% \text { in } p \\
\pm 2 \% \text { in } x \\
\pm 3 \% \text { in } y\end{array}$ & 3.4 \\
\hline Mullins, Ziegler ${ }^{34}$ & 50 & 0 & $86-108$ & $2.0-12$ & $0.002-0.02$ & $\left\{\begin{array}{l} \pm 0.03 \mathrm{~K} \text { in } T \\
\pm 0.5 \% \text { in } p \\
\pm 1-2 \% \text { in } x, y\end{array}\right.$ & 3.6 \\
\hline Sinor, Kurata ${ }^{35}$ & 29 & 0 & $93-148$ & $1.7-14$ & & $\left\{\begin{array}{l} \pm 0.5 \% \text { in } p \\
\pm 1 \% \text { in } x, y\end{array}\right.$ & 12.0 \\
\hline Skripka, Lobanova ${ }^{36}$ & 77 & 64 & $90-115$ & $2.9-22$ & $0.0005-0.002$ & \pm 0.02 vol. $\%$ in $x, y$ & 3.5 \\
\hline Streett ${ }^{37}$ & 56 & 48 & $91-148$ & $1.4-69$ & $0.002-0.44$ & $\left\{\begin{array}{l} \pm 0.02 \mathrm{~K} \text { in } T \\
\pm 2 \mathrm{~mol} \% \text { in } x, y \\
\pm 0.1 \% \text { in } p\end{array}\right.$ & 15.0 \\
\hline Streett, Hill ${ }^{38}$ & 202 & 176 & $91-160$ & $0.6-422$ & $0.02-0.60$ & $\pm 0.01 \mathrm{~K}$ in $T$ & 15.0 \\
\hline Streett, Erickson ${ }^{39}$ & 81 & 74 & $150-199$ & $386-1048$ & $0.27-0.72$ & $\begin{array}{c} \pm 0.1 \mathrm{~mol} \% \text { in } x, y \\
\mathrm{~N}^{\prime} / \mathrm{A}^{\mathrm{b}}\end{array}$ & 7.7 \\
\hline \multicolumn{8}{|c|}{$\rho p T$ data } \\
\hline Blancett et al. ${ }^{40}$ & 288 & 288 & $223-323$ & $0.3-73$ & $0.21-0.80$ & $\left\{\begin{array}{l} \pm 0.03 \mathrm{~K} \text { in } T \\
\pm 0.06 \% \text { in } Z\end{array}\right.$ & 0.72 \\
\hline Kanishev, Pitaevskaya ${ }^{41}$ & 41 & 41 & 373,473 & $50-180$ & $0.66,0.95$ & $\mathrm{~N} / \mathrm{A}^{\mathrm{b}}$ & 1.8 \\
\hline Kosov, Brovanov ${ }^{42}$ & 59 & 59 & $293-353$ & $29-59$ & $0.24-0.79$ & $\left\{\begin{array}{l} \pm 0.05 \mathrm{~K} \text { in } T \\
\pm 0.3 \% \text { in } \rho\end{array}\right.$ & 2.2 \\
\hline Maslennikova et al. ${ }^{43}$ & 116 & 116 & $293-423$ & $180-800$ & $0.31,0.74$ & $\pm 0.5 \%$ in $\rho$ & 2.4 \\
\hline
\end{tabular}


TABLE 4 - continued from previous page

\begin{tabular}{|c|c|c|c|c|c|c|c|}
\hline Popov et al. ${ }^{44}$ & 45 & 45 & $293-673$ & $5.0-40$ & $0.11-0.98$ & $\left\{\begin{array}{l} \pm 0.05 \mathrm{~K} \text { in } T \\
\pm 0.05 \% \text { in } p \\
\pm 0.02 \% \text { in } x_{\mathrm{He}}\end{array}\right.$ & 1.3 \\
\hline Provine, Canfield ${ }^{45}$ & 212 & 212 & $143-183$ & $0.2-68$ & $0.22-0.80$ & N/A ${ }^{b}$ & 1.2 \\
\hline Vidal et $a l .{ }^{46}$ & 31 & 31 & 298 & $0.1-800$ & 0.50 & $\pm 0.2 \%$ in $\rho$ & 1.5 \\
\hline Vidal et al..$^{47}$ & 13 & 13 & 298 & $80-800$ & 0.50 & $\pm 0.2 \%$ in $\rho$ & 1.9 \\
\hline \multicolumn{8}{|c|}{ Speed of sound - $w$} \\
\hline Hanayama $^{48}$ & 51 & 27 & 298 & $109-1972$ & $0.50-0.90$ & $\pm 0.5 \%$ in $w$ & 5.1 \\
\hline Kachanov et al. ${ }^{49}$ & 22 & 20 & $298-422$ & $100-700$ & 0.21 & $\pm 0.4 \%-0.63 \%$ in $w$ & 1.3 \\
\hline Nishitake, Hanayama ${ }^{50}$ & 47 & 47 & 298 & $201-1696$ & $0.50-0.90$ & $\pm 0.5 \%$ in $w$ & 11.0 \\
\hline Vidal et $a l .{ }^{47}$ & 13 & 13 & 298 & $80-800$ & 0.50 & $\pm 0.2 \%$ in $w$ & 2.4 \\
\hline \multicolumn{8}{|c|}{ Second virial coefficient - $B$} \\
\hline Blancett et al. ${ }^{40}$ & 15 & 0 & $223-323$ & & & \multirow{2}{*}{$\begin{array}{l}\left\{\begin{array}{l} \pm 0.03 \mathrm{~K} \text { in } T \\
\pm 0.3 \% \text { in } B\end{array}\right. \\
\pm 5 \% \text { in } B\end{array}$} & 21.0 \\
\hline Brewer, Vaughn ${ }^{29}$ & 8 & 0 & $148-323$ & & & & 11.0 \\
\hline Kalfoglou $^{51}$ & 60 & 0 & $303-773$ & & & $\pm 0.86 \%-1.31 \%$ in $B$ & 16.9 \\
\hline Knobler et al. ${ }^{31}$ & 1 & 0 & 90 & & & $\pm 2-3 \%$ in $B$ & 6.1 \\
\hline Martin $^{52}$ & 3 & 0 & $290-320$ & & & greater than $1.2 \%$ & 5.9 \\
\hline Tanner ${ }^{53}$ & 14 & 0 & 298 & & & $\mathrm{~N} / \mathrm{A}^{\mathrm{b}}$ & 18.9 \\
\hline
\end{tabular}

a average absolute deviation (AAD) of the data set from values calculated with EOS given in Eq. (9)

$\mathrm{b}$ undefined or poor uncertainty analysis

TABLE 5: Available and used data for the development of the equations of state for $\mathrm{Ne}-\mathrm{Ar}$

\begin{tabular}{|c|c|c|c|c|c|c|c|}
\hline \multirow[b]{2}{*}{ authors } & \multicolumn{2}{|c|}{ data points } & \multirow[b]{2}{*}{$T / \mathrm{K}$} & \multirow[b]{2}{*}{$p / \mathrm{MPa}$} & \multirow[b]{2}{*}{$x_{\mathrm{Ne}}$} & \multirow[b]{2}{*}{ author claimed uncertainty } & \multirow[b]{2}{*}{$\mathrm{AAD}^{\mathrm{a}} / \%$} \\
\hline & available & $\overline{\text { used }}$ & & & & & \\
\hline \multicolumn{8}{|c|}{ VLE data } \\
\hline Skripka, Lobanova ${ }^{36}$ & 84 & 54 & $91-120$ & $2.9-20$ & $0.03-0.31$ & \multirow{3}{*}{$\begin{array}{l} \pm 0.02 \text { vol. } \% \text { in } x, y \\
\left\{\begin{array}{l} \pm 0.01 \mathrm{~K} \text { in } T \\
\pm 0.01 \mathrm{MPa} \text { in } p \\
\mathrm{~N} / \mathrm{A}^{\mathrm{b}}\end{array}\right. \\
\begin{array}{c} \pm 0.1 \% \text { in } p\end{array}\end{array}$} & 8.0 \\
\hline Streett ${ }^{54}$ & 54 & 53 & $84-130$ & $0.4-7.3$ & $0.05-0.73$ & & 11.0 \\
\hline Streett ${ }^{55}$ & 37 & 36 & $95-130$ & $7.5-62$ & $0.09-0.57$ & & 12.0 \\
\hline Streett, Hill ${ }^{56}$ & 58 & 58 & $87-93$ & $6.4-103$ & $0.002-0.09$ & $\left\{\begin{array}{l} \pm 0.1 \% \text { in } p \\
\pm 0.02 \mathrm{~K} \text { in } T\end{array}\right.$ & 6.7 \\
\hline Trappeniers, Schouten ${ }^{57}$ & 67 & 59 & $93-138$ & $0.5-101$ & $0.002-0.57$ & $\begin{array}{l} \pm 0.1 \mathrm{~mol} \% \text { in } x, y \\
\pm 0.1 \mathrm{~mol} \% \text { in } x, y\end{array}$ & 13.0 \\
\hline \multicolumn{8}{|c|}{$\rho p T$ data } \\
\hline Kestin et al. ${ }^{23}$ & 21 & 21 & 298 & $0.4-13.7$ & $0.23,0.73$ & $\pm 0.1 \%$ in $\rho$ & 0.43 \\
\hline Streett ${ }^{55}$ & 109 & 107 & $102-121$ & $3.0-55.2$ & $0.04-0.50$ & $\pm 1 \%$ in $\rho$ & 2.5 \\
\hline Vidal et al. ${ }^{46}$ & 31 & 31 & 298 & $0.1-800$ & 0.50 & $\pm 0.2 \%$ in $\rho$ & 1.6 \\
\hline Vidal et al. $^{47}$ & 13 & 13 & 298 & $80-800$ & 0.50 & $\pm 0.2 \%$ in $\rho$ & 2.8 \\
\hline \multicolumn{8}{|c|}{ Speed of sound $-w$} \\
\hline Konovodchenko et al. ${ }^{58}$ & 10 & 0 & 102,121 & $1.3-15$ & 0.22 & $\mathrm{~N} / \mathrm{A}^{\mathrm{b}}$ & 60.0 \\
\hline Vidal et al. $^{47}$ & 13 & 13 & 298 & $80-800$ & 0.50 & $\pm 0.2 \%$ in $w$ & 1.2 \\
\hline \multicolumn{8}{|c|}{ Second virial coefficient - $B$} \\
\hline Brewer, Vaughn ${ }^{29}$ & 9 & 0 & $123-323$ & & & $\pm 5 \%$ in $B$ & 9.7 \\
\hline Knobler et al. ${ }^{31}$ & 1 & 0 & 90 & & & $\pm 2-3 \%$ in $B$ & 5.9 \\
\hline
\end{tabular}

${ }^{a}$ average absolute deviation (AAD) of the data set from values calculated with EOS given in Eq. (9)

${ }^{\mathrm{b}}$ undefined or poor uncertainty analysis

Even though the virial coefficients were collected, and are presented in Tables 3, 4, and 5, they were not fitted. Physics dictates that $B_{12}$ should only be a function of temperature, but our mixing rule also produces a dependence on composition in the multi-fluid models.

When compared to the pure fluids, the region of existing state points is always broader for mixtures, since it is also composition-dependent. It is therefore more difficult to cover a comparable number of states for mixtures as for pure fluids.
The equilibrium data available for the mixture of helium-neon are limited in pressure up to $20 \mathrm{MPa}$. Therefore, the shape of the phase envelope at higher pressures is unknown. However, a pressure of $20 \mathrm{MPa}$ is higher than most engineering applications, and the model shows satisfactory accuracy at lower pressures with the extrapolation behavior being acceptable. Both the equilibrium data, and $\rho p T$ data for helium-argon and neon-argon mixtures reach higher pressures up to $1 \mathrm{GPa}$ for helium-argon, and $100 \mathrm{MPa}$ for neon-argon. 
TABLE 6: Binary specific parameters obtained in this work

\begin{tabular}{cccccc}
\hline \hline$i-j$ & $\beta_{T, i j}$ & $\gamma_{T, i j}$ & $\beta_{v, i j}$ & $\gamma_{v, i j}$ & $F_{i j}$ \\
\hline${ }^{4} \mathrm{He}-\mathrm{Ne}$ & 0.793 & 0.728 & 1.142 & 0.750 & 1.0 \\
${ }^{4} \mathrm{He}-\mathrm{Ar}$ & 1.031 & 1.113 & 1.048 & 0.862 & 1.0 \\
$\mathrm{Ne}-\mathrm{Ar}$ & 1.033 & 0.967 & 0.919 & 1.035 & 1.0 \\
\hline \hline
\end{tabular}

\subsection{Fluid properties scaling}

Depending on the mixture, the phase envelope varies in shape; it can be either closed or open, it can either have the GGE locus or just the VLE dome. The name gas-gas equilibrium implies that a phase separation occurs beyond the critical temperature of the heavier component. ${ }^{59}$ For the heliumargon mixture, the gas-gas coexistence region detaches from the vapor-liquid region with increasing temperature. When temperature further increases, the regions separate completely (see two $148 \mathrm{~K}$ isotherms in Fig. 1d - VLE closing at $27 \mathrm{MPa}$, and GGE opening at $57 \mathrm{MPa}$ ). The vapor-liquid coexistence terminates at $150 \mathrm{~K}$ and for higher temperatures only the gasgas equilibria exist. Helium often shows this type of behavior when mixed with other substances. ${ }^{59,60}$ It is therefore probable that two other mixtures considered in this paper behave similarly but this question is not further investigated due to the lack of high-pressure data for ${ }^{4} \mathrm{He}-\mathrm{Ne}$ and $\mathrm{Ne}-\mathrm{Ar}$. Scaling the properties of helium- 4 and neon with any physical theory in the regions of missing data can be challenging because of the quantum phenomena influencing the fluid's behavior. Classical or quantum effects will dominate depending on the length scale of interactions vs. the thermal de Broglie wavelength

$$
\lambda_{\mathrm{th}}=\sqrt{\frac{h^{2}}{2 \pi m k_{\mathrm{B}} T}},
$$

where $T$ is the temperature at which $\lambda_{\text {th }}$ is calculated, $h=$ $6.62607015 \times 10^{-34} \mathrm{~J} \mathrm{~s}$ is the Planck constant, ${ }^{61} \mathrm{~m}=M / N_{\mathrm{A}}$ is the particle mass with molar mass $M$ given in Table $1, N_{\mathrm{A}}=$ $6.02214076 \times 10^{23} \mathrm{~mol}^{-1}$ is the Avogadro constant, ${ }^{61}$ and $k_{\mathrm{B}}=1.380649 \times 10^{-23} \mathrm{~J} \mathrm{~K}^{-1}$ is the Boltzmann constant. ${ }^{61}$

Quantum effects are important in determining the thermodynamics of helium, and to a lesser extent neon; argon can be considered classical for most practical purposes. Despite dealing with the fluids that show high and moderate quantum effects, the discussion on the quantum physics is secondary, since the presented equations are empirical and the question about the origins of the intermolecular forces is irrelevant.

\section{RESULTS}

In addition to the four reducing parameters from Table 6, the model optimization and development included deriving the departure functions according to Eq. (7). The temperature and density dependent parts of the departure functions for three binary fluid mixtures are presented in Table 7. The phase behavior of the EOS is presented in Fig. 1 and is analyzed further in this section. To illustrate the accuracy of the equations, deviations of thermodynamic properties calculated with the EOS are compared against the experimental values.

Along with the errors discussed below, each data set has a measurement uncertainty. The uncertainties claimed by the authors should be viewed skeptically, especially in light of reporting standards for uncertainty that have evolved over time. With this in mind, the uncertainties specified by the authors in their publications are listed in Tables 3, 4, and 5. The largest uncertainty for the equilibria measurements is attributed to composition and varies from $0.1 \%$ to $3 \%$ in mole fraction for bubble points $x$ and dew points $y$. Regarding the density measurements, the uncertainty is often claimed to be on the order of $0.1 \%$, except for $1 \%$ for $\mathrm{Ne}-\mathrm{Ar}$ densities.

\subsection{Uncertainty discussion for single-phase}

Fig. 4 presents the EOS deviations from the data used in the development of each equation. The density deviations for the helium-neon equation are smaller than for the other two pairs: $0.5 \%$ dropping the lower accuracy data at $30-40 \mathrm{~K}$. However, similarly as with the equilibrium data, the pressure range for this binary pair is also more narrow for $\rho p T$ when compared to the other two mixtures. For neon-argon, the density measurements reach $55 \mathrm{MPa}$ and for helium-argon, they go up to $1 \mathrm{GPa}$. When comparing the equation error for similar low-pressure data $(0-10 \mathrm{MPa})$, the helium-argon EOS has errors of $0.5 \%-2.5 \%$ for $95 \%$ of data points used in the EOS development; and neon-argon has errors of $3 \%$ for $90 \%$ of density data.

The deviations in density at lower pressures for each EOS are comparable with the measurement uncertainties presented in Tables 3, 4, and 5. However, for pressures above $20 \mathrm{MPa}$, the equations deviate from data more than the specified uncertainties.

At the same time, the temperature regions of data availability has to be taken into consideration. For the helium-argon mixture the data set is broad, not only in pressure but also in temperature (starts close to the two-phase region and reaches $573 \mathrm{~K})$. It is not the case for helium-neon, which is missing accurate low-temperature data, nor for neon-argon, where density measurements are narrow in temperature range. The exact pressure and temperature ranges are presented in Tables 3, 4, and 5 and Fig. 4.

\subsection{Uncertainty discussion at phase boundary}

When applying the isothermal error calculations based on the comparison of the bubble or dew pressures for a given mixture composition, very large calculated deviations can be obtained when the isotherm in the $\log p-x$ plane is vertical or very steep, although the data point may be still very close to the phase envelope. This is simply a degeneracy in the means of error quantification. 


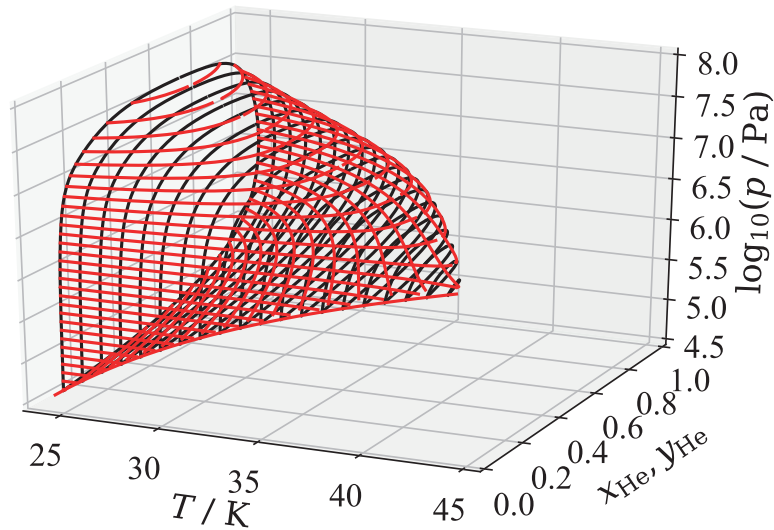

(a) Helium-neon closed phase envelope

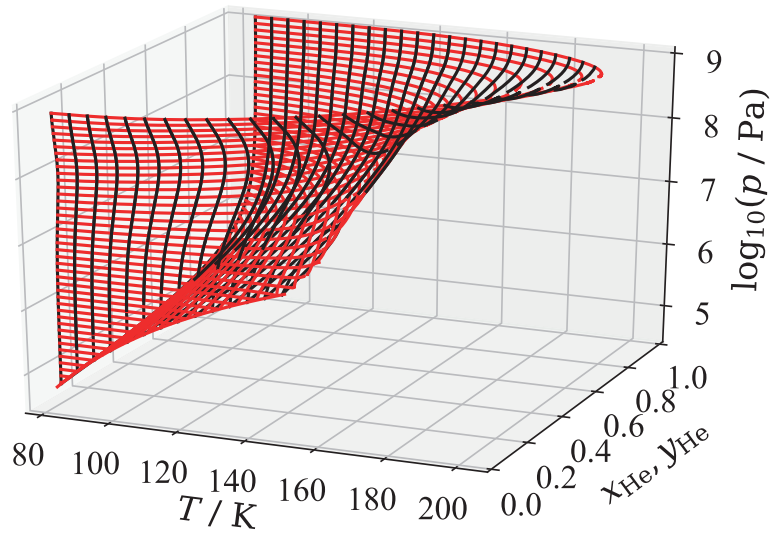

(c) Class III ${ }^{59}$ phase envelope of helium-argon with GGE opening

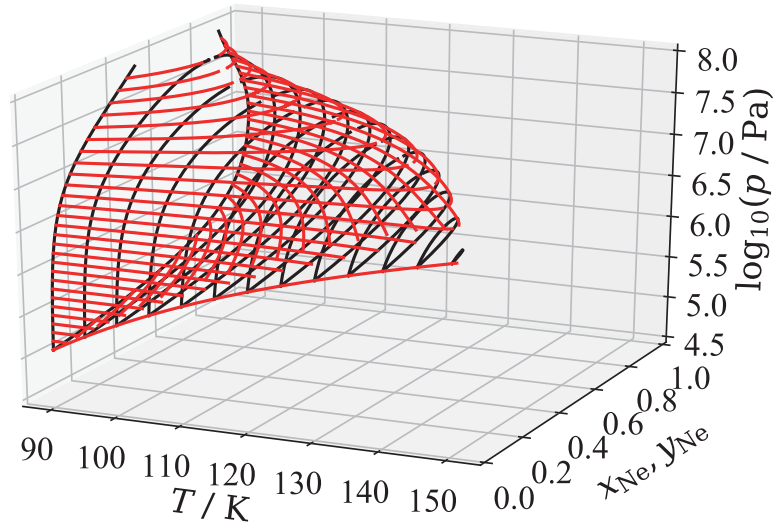

(e) Neon-argon phase envelope with opening at higher pressures

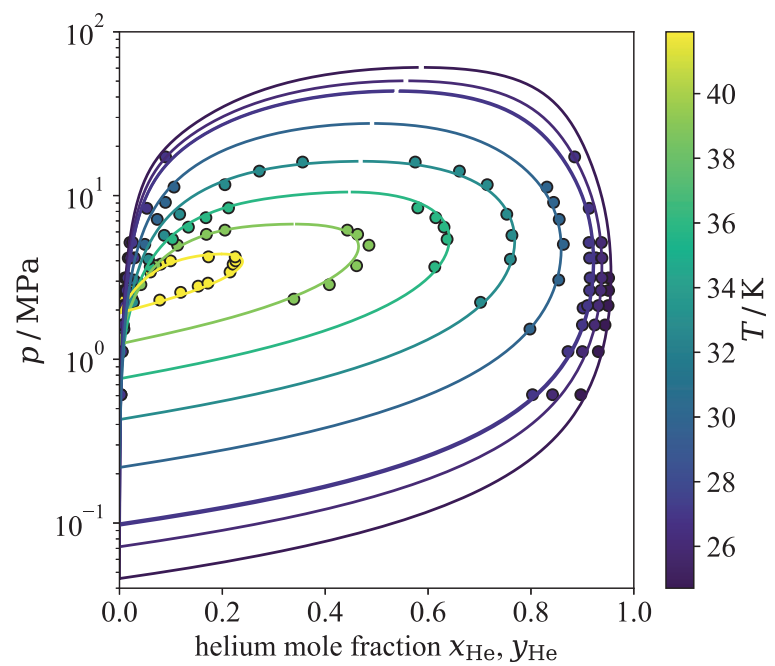

(b) VLE isotherms for helium-neon with experimental data plotted in respective temperature color code

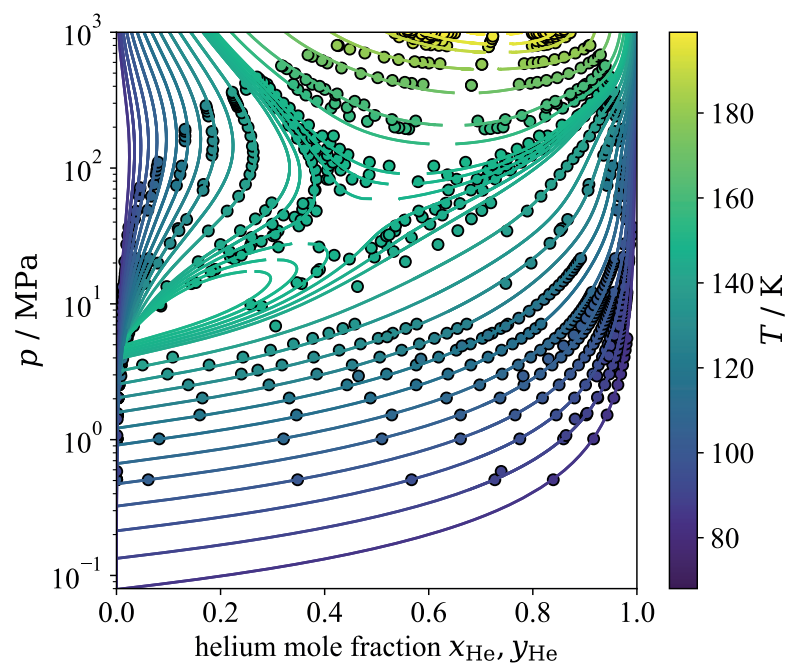

(d) VLE and GGE isotherms for helium-argon and experimental data

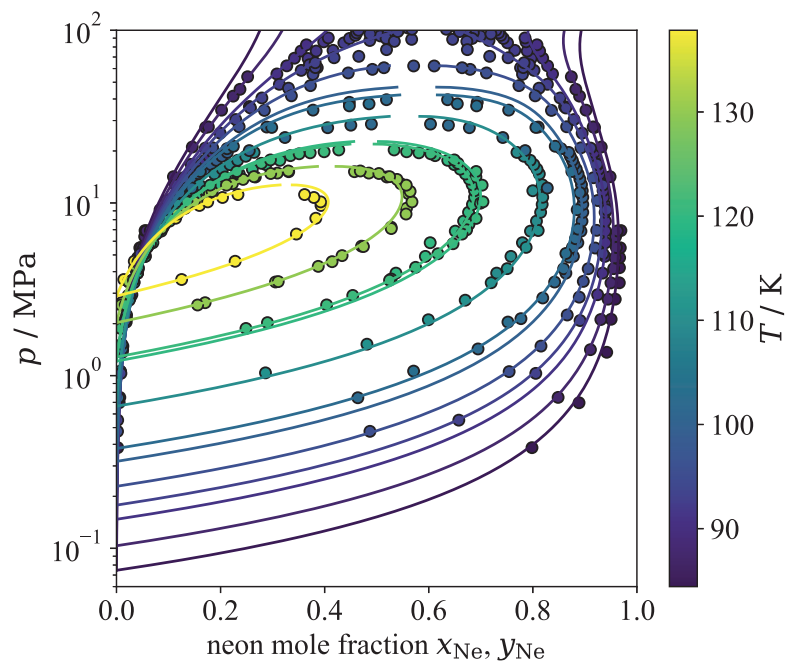

(f) VLE isotherms for neon-argon and experimental data

FIG. 1: The phase envelopes for three binary mixtures shown in three-dimensional space of $p-T-x$ with isobars in red, and isotherms in black $(\mathrm{a}, \mathrm{c}, \mathrm{e})$. Their projection on 2D plane of $p-x(\mathrm{~b}, \mathrm{~d}, \mathrm{f})$ constructed with the algorithm for equilibria of binary mixtures ${ }^{62}$. 
TABLE 7: Departure function coefficients

\begin{tabular}{|c|c|c|c|c|c|c|c|}
\hline \multicolumn{8}{|c|}{$\overline{{ }^{4} \mathrm{He}-\mathrm{Ne}}$} \\
\hline$k$ & $N_{k}$ & $t_{k}$ & $d_{k}$ & $\eta_{k}$ & $\beta_{k}$ & $\gamma_{k}$ & $\varepsilon_{k}$ \\
\hline$\overline{1}$ & -4.346849 & $\frac{n}{1.195}$ & $\frac{n}{1}$ & 0 & $\frac{T-1}{0}$ & $\frac{\pi n}{0}$ & 0 \\
\hline 2 & -0.884378 & 1.587 & 2 & 0 & 0 & 0 & 0 \\
\hline 3 & 0.258416 & 1.434 & 3 & 0 & 0 & 0 & 0 \\
\hline 4 & 3.502188 & 1.341 & 1 & 0.157 & 0.173 & 1.310 & 1.032 \\
\hline 5 & 0.831330 & 1.189 & 2 & 0.931 & 1.070 & 1.356 & 1.978 \\
\hline 6 & 2.740495 & 1.169 & 3 & 0.882 & 0.695 & 1.596 & 1.966 \\
\hline 7 & -1.582230 & 0.944 & 4 & 0.868 & 0.862 & 1.632 & 1.709 \\
\hline 8 & -0.304897 & 1.874 & 4 & 0.543 & 0.971 & 0.766 & 0.583 \\
\hline \multicolumn{8}{|c|}{${ }^{4} \mathrm{He}-\mathbf{A r}$} \\
\hline$k$ & $N_{k}$ & $t_{k}$ & $d_{k}$ & $\eta_{k}$ & $\beta_{k}$ & $\gamma_{k}$ & $\varepsilon_{k}$ \\
\hline 1 & -2.643654 & 1.030 & 1 & 0 & 0 & 0 & 0 \\
\hline 2 & -0.347501 & 0.288 & 2 & 0 & 0 & 0 & 0 \\
\hline 3 & 0.201207 & 0.572 & 3 & 0 & 0 & 0 & 0 \\
\hline 4 & 1.171326 & 1.425 & 1 & 0.371 & 0.320 & 1.409 & 0.378 \\
\hline 5 & 0.216379 & 1.987 & 1 & 0.081 & 1.247 & 1.709 & 0.741 \\
\hline 6 & 0.561370 & 0.024 & 2 & 0.375 & 1.152 & 0.705 & 0.322 \\
\hline 7 & 0.182570 & 1.434 & 3 & 0.978 & 0.245 & 1.162 & 1.427 \\
\hline 8 & 0.017879 & 0.270 & 4 & 0.971 & 1.030 & 0.869 & 2.088 \\
\hline \multicolumn{8}{|c|}{$\mathbf{N e}-\mathbf{A r}$} \\
\hline$k$ & $N_{k}$ & $t_{k}$ & $d_{k}$ & $\eta_{k}$ & $\beta_{k}$ & $\gamma_{k}$ & $\varepsilon_{k}$ \\
\hline$\overline{1}$ & -1.039686 & $\frac{n}{0.723}$ & 1 & 0 & 0 & $\frac{\pi}{0}$ & 0 \\
\hline 2 & 0.593776 & 1.689 & 2 & 0 & 0 & 0 & 0 \\
\hline 3 & -0.186531 & 1.365 & 3 & 0 & 0 & 0 & 0 \\
\hline 4 & -0.223315 & 0.201 & 1 & 1.018 & 0.360 & 1.119 & 2.490 \\
\hline 5 & 0.160847 & 0.164 & 2 & 0.556 & 0.373 & 1.395 & 1.202 \\
\hline 6 & 0.405228 & 0.939 & 2 & 0.221 & 0.582 & 1.010 & 2.468 \\
\hline 7 & -0.264563 & 1.690 & 3 & 0.862 & 0.319 & 1.227 & 0.837 \\
\hline 8 & -0.033569 & 1.545 & 4 & 0.809 & 0.560 & 1.321 & 2.144 \\
\hline
\end{tabular}

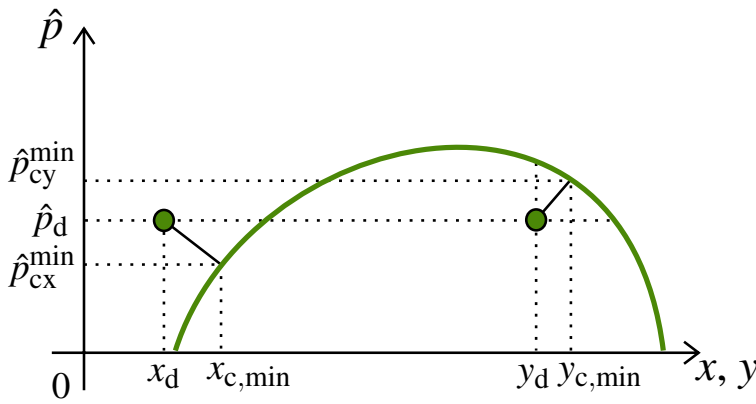

FIG. 2: Schematic representation of the orthogonal error calculations for the phase envelopes. Two experimental compositions for liquid and vapor from one measurement are marked with circles (the same pressure and temperature) and the respective isotherm evaluated with the EOS is plotted in two-dimensional space of reduced pressure $\hat{p}=p / p_{\mathrm{r}}$ and mole fraction in liquid $x$ and vapor $y$.

In order to evaluate the phase equilibria errors, the orthogonal length scale for data versus the EOS was defined. The error is calculated by finding the smallest distance between the experimental data point $\left(\left(x_{\mathrm{d}}, \hat{p}_{\mathrm{d}}\right), T_{\mathrm{d}}\right)$ and the respective isotherm evaluated with given $\operatorname{EOS}\left(\left(x_{\mathrm{c}}, \hat{p}_{\mathrm{c}}\right), T_{\mathrm{c}}\right)$, where $T_{\mathrm{d}}=$ $T_{\mathrm{c}}$, and $\hat{p}=p / p_{\mathrm{r}}$. The orthogonal error itself should be dimen- sionless, therefore its evaluation in the pressure-mole fraction plane requires the pressure to also be dimensionless, therefore reduced. After comparing the impact of the reducing scales on the error representation, the logarithmic reducing scale has been selected among the linear, and density-temperature reducing scale $\left(p_{\mathrm{r}}=p\left(\rho_{\mathrm{r}}, T_{\mathrm{r}}\right)\right)$

$$
\left\{\begin{array}{l}
p_{\mathrm{r}, \mathrm{x}}=\exp \left(x_{1} \ln \left(p_{\mathrm{c} 1}\right)+x_{2} \ln \left(p_{\mathrm{c} 2}\right)\right) \\
p_{\mathrm{r}, \mathrm{y}}=\exp \left(y_{1} \ln \left(p_{\mathrm{c} 1}\right)+y_{2} \ln \left(p_{\mathrm{c} 2}\right)\right)
\end{array},\right.
$$

where $p_{\mathrm{r}, \mathrm{x}}$ reduces the pressure for the bubble points and $p_{\mathrm{r}, \mathrm{y}}$ reduces the pressure for the dew points.

The error itself is defined as a sum of distances between the data point $x_{\mathrm{d}}$ and the closest point from the respective isotherm in the earlier defined $\hat{p}-x$ plane

$$
\left\{\begin{array}{l}
\operatorname{err}_{\mathrm{x}}^{\mathrm{vle}}= \pm \sqrt{\left(x_{\mathrm{d}}-x_{\mathrm{c}}^{\min }\right)^{2}+\left(\ln \left(\hat{p}_{\mathrm{d}}\right)-\ln \left(\hat{p}_{\mathrm{c}, \mathrm{x}}^{\min }\right)\right)^{2}} \\
\operatorname{err}_{\mathrm{y}}^{\mathrm{vle}}= \pm \sqrt{\left(y_{\mathrm{d}}-y_{\mathrm{c}}^{\mathrm{min}}\right)^{2}+\left(\ln \left(\hat{p}_{\mathrm{d}}\right)-\ln \left(\hat{p}_{\mathrm{c}, \mathrm{y}}^{\min }\right)\right)^{2}}
\end{array}\right.
$$

where $x_{\mathrm{d}}$ and $\hat{p}_{\mathrm{d}}$ are molar composition and reduced pressure for the experimental data point, and $x_{\mathrm{c}}^{\mathrm{min}}$ and $p_{\mathrm{c}, \mathrm{x}}^{\min }$ are molar composition and reduced pressure evaluated with the HEOS at the same temperature as the data point. This error definition is represented schematically in Fig. 2. The sign convention is 

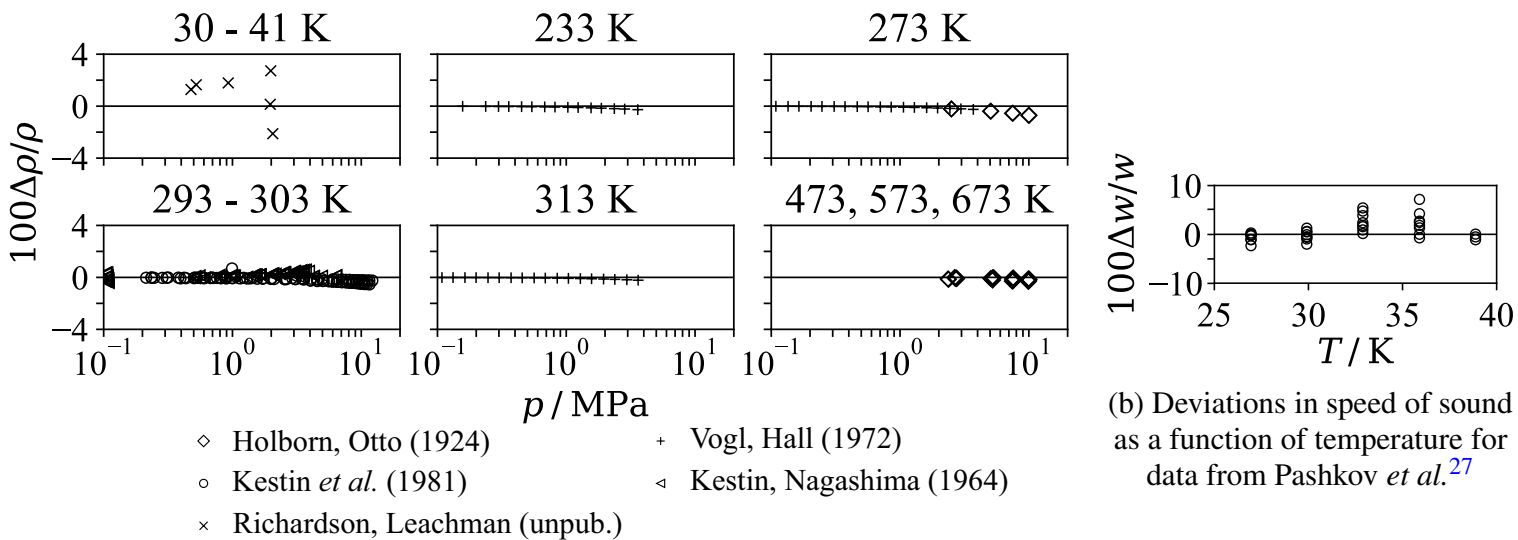

(b) Deviations in speed of sound as a function of temperature for data from Pashkov et l. $^{27}$

(a) Deviations in density as a function of pressure presented as percentage differences between calculated and measured density

FIG. 3: Relative deviations of the ${ }^{4} \mathrm{He}-\mathrm{Ne}$ equation to data

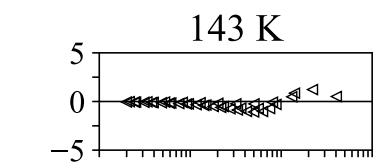

$158 \mathrm{~K}$

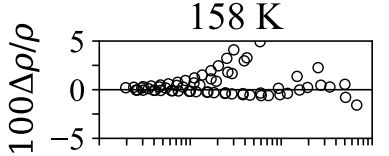

$183 \mathrm{~K}$

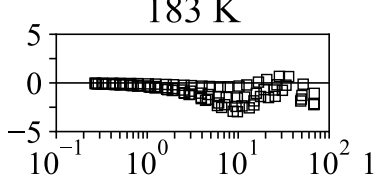

$\times \quad$ Blancett et al. (1970)

+ Kosov, Brovanov (1975)

$\diamond \quad$ Kanishev, Pitaevskaya (1980)

- Maslennikova et al. (1978)
$223 \mathrm{~K}$

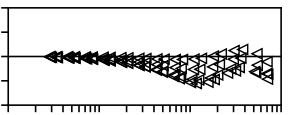

$273 \mathrm{~K}$

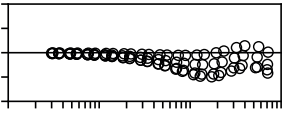

$573 \mathrm{~K}$

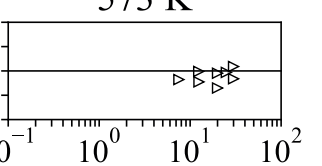

$p / \mathrm{MPa}$

- Popov et al. (1970)

$\triangleleft$ Provine et al. (1971)

$\nabla \quad$ Vidal et al. (1986)

$\triangleright \quad$ Vidal et al. (1991)
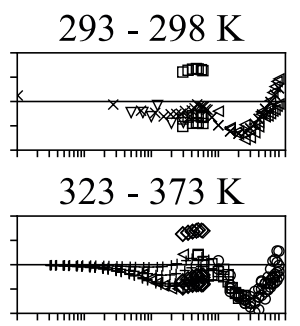

$423-473 \mathrm{~K}$

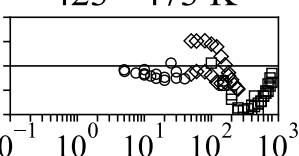

Hanayama (1978)

+ Kachanov et al. (1983)

- Nishitake, Hanayama (1977)

$\diamond$ Vidal et al. (1991)

(b) Deviations in speed of sound as a function of temperature

(a) Deviations in density calculations for pressures up to $100 \mathrm{MPa}$ in two left columns and up to $1 \mathrm{GPa}$ in the right column

FIG. 4: Relative deviations of the ${ }^{4} \mathrm{He}-\mathrm{Ar}$ equation to data
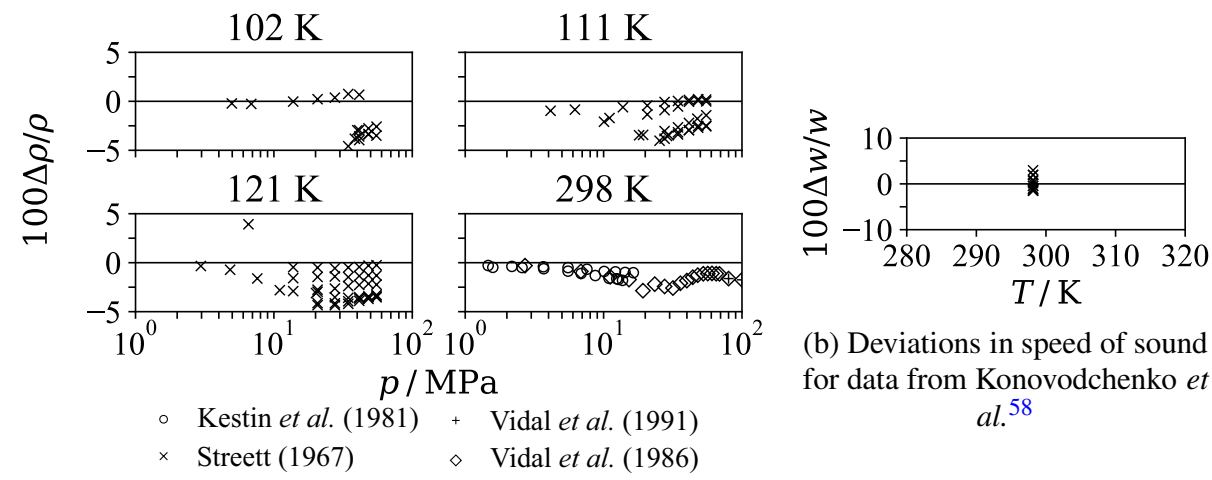

(b) Deviations in speed of sound for data from Konovodchenko $e t$

$$
a .^{58}
$$

(a) Deviations in density calculations

FIG. 5: Relative deviations of the $\mathrm{Ne}-\mathrm{Ar}$ equation to data 


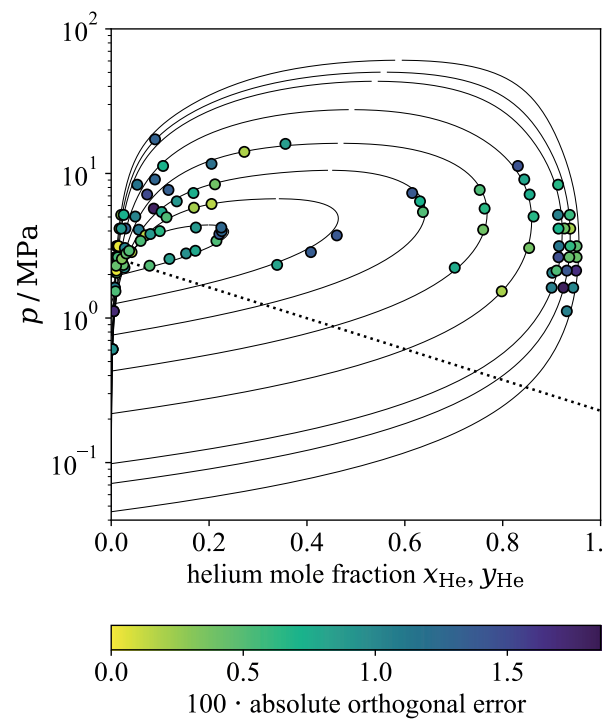

(a) Helium-neon phase envelope with maximal orthogonal error of 1.89

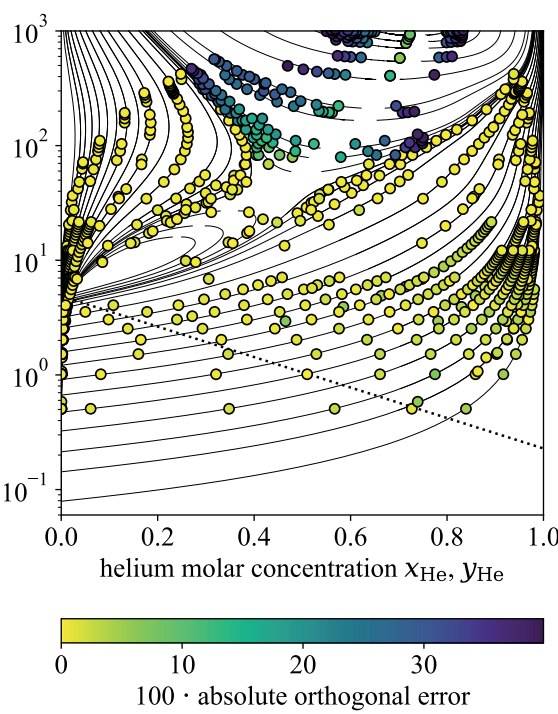

(b) Helium-argon phase envelope with maximal orthogonal error of 39.99

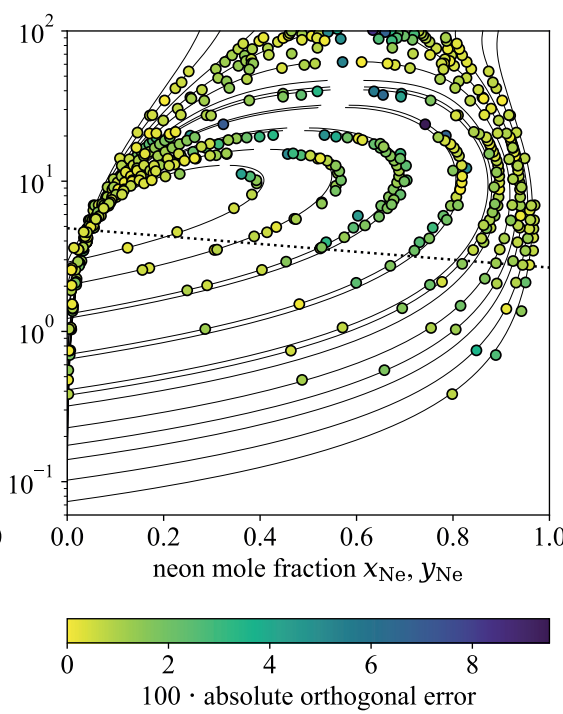

(c) Neon-argon phase envelope with maximal orthogonal error of 9.29

FIG. 6: Three mixture phase envelopes with color scales representing the absolute orthogonal error values plotted for $99.99 \%$ of data points for ${ }^{4} \mathrm{He}-\mathrm{Ne}, 91.36 \%$ of data points for ${ }^{4} \mathrm{He}-\mathrm{Ar}$, and $99.23 \%$ of data points for $\mathrm{Ne}-\mathrm{Ar}$. The dotted line in each figure represents the reducing pressure scale from Eq. (11)

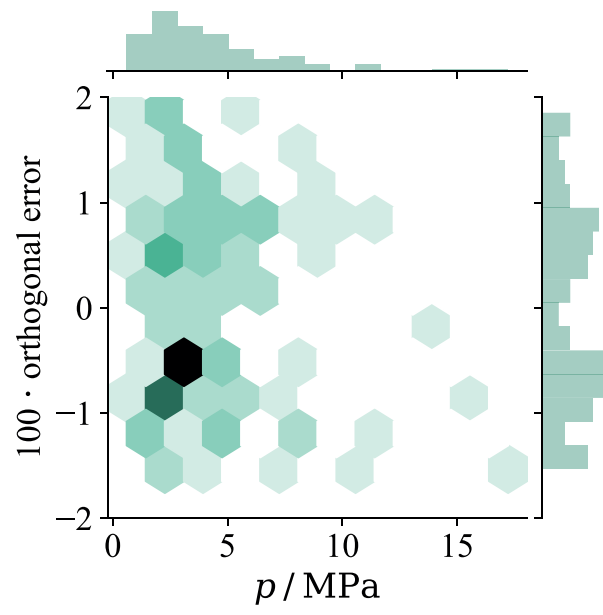

(a) Helium-neon orthogonal error plotted for $99.99 \%$ of data points used for EOS development

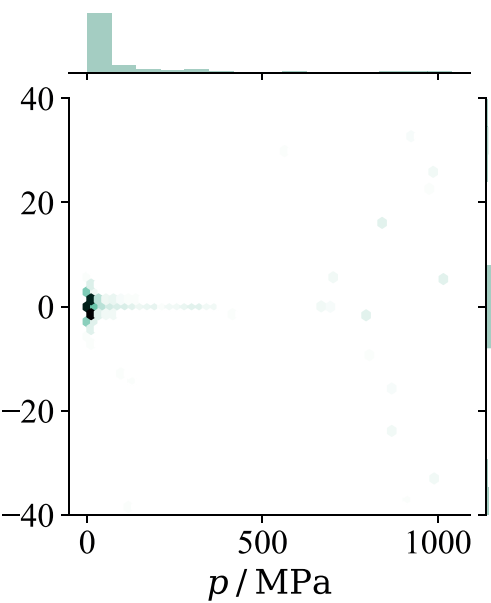

(b) Helium-argon orthogonal error plotted for $91.36 \%$ of data points used for EOS development

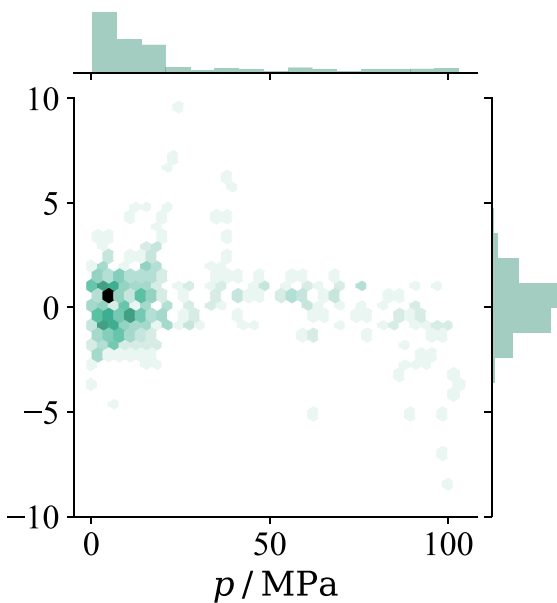

(c) Neon-argon orthogonal error plotted for $99.23 \%$ of data points used for EOS development

FIG. 7: Vapor-liquid and gas-gas equilibria orthogonal error values for three binary mixtures. Color intensity increases with increasing number of points in the hexagonal unitary area. The marginal histograms represent the number of data points in different data bins in whole pressure range (x-axis) and orthogonal error range (y-axis)

chosen so the positive error represents the EOS calculating too large a pressure when compared to data, and negative when calculating too small a pressure. It is important to highlight that the compositions at the minimum point and experimental point can be different. Results for described error calculations are presented in Fig. 6 and 7. To our knowledge, this is the first time that an error metric like this has been used to quantify error from mixture equations of state.
While the composition for the phase equilibrium calculations is always in the range of $[0,1]$, the logarithm of reduced pressure $\ln (\hat{p})$ can reach values up to 7 for the absolute pressure of $1 \mathrm{GPa}$ and defined pressure metric. Therefore, the error definition from Eq. (12), and the chosen pressure metric emphasize the pressure error more than the composition error. Even though all the data were fitted to the ${ }^{4} \mathrm{He}-\mathrm{Ar}$ EOS, it largely deviates from the experimental points at very 


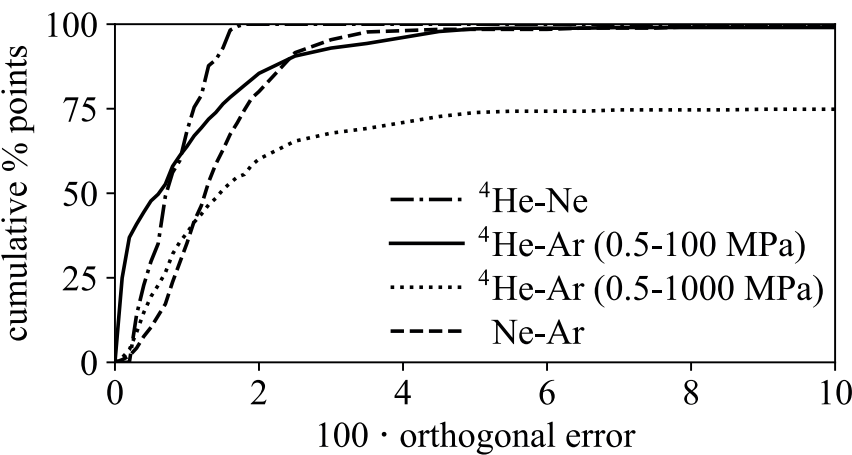

FIG. 8: Cumulative percentage of points with error less than the specified value of the VLE orthogonal error for each EOS. ${ }^{4} \mathrm{He}-\mathrm{Ar}$ errors are considered for two pressure ranges: complete data availability pressure range and up to $100 \mathrm{MPa}$ with smaller orthogonal error

high pressures. Those high deviations are visible in Fig. 6c as the dark blue circles and in Fig. $7 \mathrm{~b}$ as the faint hexagons with large orthogonal error. Additional error comparison for helium-argon at pressures below $100 \mathrm{MPa}$ is given in Fig. 8, where it shows very satisfactory agreement between the data and the EOS in limited pressure range, and worse EOS behavior for high pressure.

\subsection{Ternary mixture}

With the three binary fluid mixture equations developed, the model for ternary mixture of all constituents is valid from the theoretical point of view for the Helmholtz energy EOS. Even though it is mathematically valid, no experimental data for the ternary mixture were found to compare against the equation. The accuracy of the EOS for the ternary mixture of heliumneon-argon remains unknown.

\subsection{Validation data}

When implementing new equations of state in any software, the EOS should be validated against the data points provided to verify if their implementation was successful. If the software uses the same pure fluid equations as given in this work (helium- $4,{ }^{11}$ neon, ${ }^{12}$ and $\operatorname{argon}{ }^{13}$ ), the implementation of mixture equations should return the same results in pressure calculations up to the last significant digit. A script in the Python language is provided in the supporting information in which calculations with CoolProp (version 6.3.0) reproduce exactly the values in Table 8 . The fluid files used are also provided in text form and loaded at runtime. The calculated values in REFPROP 10.0 will be slightly different due to truncation of the reducing density for argon after the conversion from $\mathrm{kg} \mathrm{m}^{-3}$ to $\mathrm{mol} \mathrm{dm}^{-3}$.
TABLE 8: Data points at equimolar (0.5/0.5) composition for EOS validation

\begin{tabular}{rccc}
\hline \hline & $T / \mathrm{K}$ & $\rho /\left(\mathrm{mol} \mathrm{dm}^{-3}\right)$ & $p / \mathrm{Pa}$ \\
\hline${ }^{4} \mathrm{He}-\mathrm{Ne}$ & 200.0 & 10.0 & 18430775.292600896 \\
${ }^{4} \mathrm{He}-\mathrm{Ar}$ & 200.0 & 10.0 & 17128034.388362616 \\
$\mathrm{Ne}-\mathrm{Ar}$ & 200.0 & 10.0 & 15905875.375781253 \\
\hline \hline
\end{tabular}

\section{CONCLUSIONS}

Three equations of state explicit in the Helmholtz energy for mixtures of noble gases with high potential of application at cryogenic temperatures were developed. The equations are not limited to the cryogenic temperatures and can be successfully used at ambient and above ambient temperatures calculations at the phase equilibrium, as well as in the single phase. The EOS performances vary for each equation depending on the pressure. The ${ }^{4} \mathrm{He}-\mathrm{Ne}$ EOS shows errors in range of uncertainties of the experimental data points for both single phase and the phase envelope. ${ }^{4} \mathrm{He}-\mathrm{Ar}$ shows satisfactory performance at pressures up to $100 \mathrm{MPa}$, and increasing errors above. The $\mathrm{Ne}-\mathrm{Ar}$ EOS errors are low at the equilibrium conditions and degenerate in the single phase. Small artifacts might occur immediately above the critical points of the heavier components for given equations.

The necessary improvements introduced to the fitter let us think that development of the Helmholtz energy equations of state for further challenging mixtures should be successful.

\section{SUPPLEMENTARY MATERIALS}

The supplementary material contains files with data, constraints, and limits applied on the fitted function for every binary mixture. It also contains the hmx.bnc text file with developed equations, which can be implemented in REFPROP in the given form. The included python 3 script, together with the pure fluid files allow to validate the equations with CoolProp (version 6.3.0).

\section{ACKNOWLEDGMENTS}

This research was partially supported by EASITrain - European Advanced Superconductivity Innovation and Training. This Marie Skłodowska-Curie Action (MSCA) Innovative Training Network (ITN) has received funding from the European Union's H2020 Framework Program under Grant Agreement no. 764879.

\section{REFERENCES}

${ }^{1}$ A. Abada, M. Abbrescia, S. S. AbdusSalam, et al., Eur. Phys. J.-Spec. Top. 228, 755-1107 (2019).

${ }^{2}$ D.-Y. Peng and D. B. Robinson, Ind. Eng. Chem. 15, 59-64 (1976). 
${ }^{3}$ H. A. Lorentz, Ann. Phys. 248, 127-136 (1881).

${ }^{4}$ D. Berthelot, "Sur le mélange des gaz," Compt. Rendus 126, 1703-1706 (1898).

${ }^{5}$ I. Cullimore and E. W. Lemmon, "Preliminary equation of state for neonargon mixture," (unpublished) (2010).

${ }^{6} \mathrm{E}$. W. Lemmon, "Preliminary equation of state for helium-neon mixture," (unpublished) (2016)

${ }^{7}$ Private communication with V. L. Bondarenko, Bauman Moscow State Technical University.

${ }^{8}$ E. W. Lemmon, I. H. Bell, M. L. Huber, and M. O. McLinden, "NIST Standard Reference Database: Reference Fluid Thermodynamic and Transport Properties-REFPROP, Version 10.0, National Institute of Standards and Technology," (2018), https://www.nist.gov/srd/refprop.

${ }^{9}$ I. H. Bell, J. Wronski, S. Quoilin, and V. Lemort, Ind. Eng. Chem. Res. 53, 2498-2508 (2014).

${ }^{10}$ R. Span, R. Beckmüller, T. Eckermann, S. Herrig, S. Hielscher, A. Jäger, E. Mickoleit, T. Neumann, S. Pohl, B. Semrau, and M. Thol, "TREND. Thermodynamic Reference and Engineering Data 4.0," (2019), http://www . thermo.ruhr-uni-bochum.de/.

${ }^{11}$ D. O. Ortiz Vega, Ph.D. thesis, Texas A\&M University (2013).

${ }^{12}$ M. Thol, R. Beckmüller, R. Weiss, A. H. Harvey, E. W. Lemmon, R. T. Jacobsen, and R. Span, "Thermodynamic properties for neon for temperatures from the triple point to $700 \mathrm{~K}$ at pressures to $700 \mathrm{MPa}$," to be submitted to J. Phys. Chem. Ref. Data.

${ }^{13} \mathrm{C}$ Tegeler, R. Span, and W. Wagner, J. Phys. Chem. Ref. Data 28, 779-850 (1999).

${ }^{14} \mathrm{O}$. Kunz, R. Klimeck, W. Wagner, and M. Jaeschke, in GERG TM15, Vol. 6 (Fortschritt-Berichte VDI, 2007).

${ }^{15}$ O. Kunz and W. Wagner, J. Chem. Eng. Data 57, 3032-3091 (2012).

${ }^{16}$ I. H. Bell and E. W. Lemmon, J. Chem. Eng. Data 61, 3752-3760 (2016).

${ }^{17}$ K. Levenberg, Q. Appl. Math. 2, 164-168 (1944).

${ }^{18}$ D. W. Marquardt, J. Soc. Ind Appl. Math. 11, 431-441 (1963).

${ }^{19}$ J. W. Leachman, R. T. Jacobsen, E. W. Lemmon, and S. G. Penoncello, Thermodynamic Properties of Cryogenic Fluids (Springer International Publishing, Cham, 2017).

${ }^{20}$ C. K. Heck and P. L. Barrick, in Adv. Cryo. Eng., Vol. 12 (Springer US, 1967) pp. 714-718.

${ }^{21}$ M. Knorn, Cryogenics 7, 177 (1967)

${ }^{22}$ L. Holborn and J. Otto, Z. Angew. Phys. 23, 77-94 (1924).

${ }^{23}$ J. Kestin, Ö. Korfali, J. V. Sengers, and B. Kamgar-Parsi, Physica A 106, 415-442 (1981).

${ }^{24}$ J. Kestin and A. Nagashima, J. Chem. Phys. 40, 3648-3654 (1964).

${ }^{25}$ I. Richardson and J. W. Leachman - unpublished results, Washington State University.

${ }^{26}$ W. F. Vogl and K. R. Hall, Physica 59, 529-535 (1972)

${ }^{27}$ V. V. Pashkov, E. V. Konovodchenko, and O. V. Evdokumova, Eng. Phys. J. 4, 603-608 (1985).

${ }^{28}$ R. Berman, F. A. B. Chaves, D. M. Livesley, and C. D. Swartz, J. Phys. C. 12, 777-780 (1979).

${ }^{29}$ J. Brewer and G. W. Vaughn, J. Chem. Phys. 50, 2960-2968 (1969).

${ }^{30}$ M. B. Iomtev, A. I. Doroshenko, L. S. Kushner, K. M. A. Sarov, and L. T. Kalinichenko, "Solubility of neon in gaseous helium," Zh. Fiz. Khim. 51, 1373-1376 (1977).

${ }^{31}$ C. M. Knobler, J. J. M. Beenakker, and H. F. P. Knaap, Physica 25, 909-916 (1959).

${ }^{32}$ J. C. Mullins, Ph.D. thesis, Georgia Institute of Technology, Atlanta (1965).

${ }^{33}$ J. C. Mullins and W. T. Ziegler, "The system helium-argon from $65^{\circ}$ to $140^{\circ} \mathrm{K}$ up to pressures of $120 \mathrm{~atm}$. Correlation of available phase equilibrium data," Technical report 3 (project A-764), pp. 9 (Georgia Institute of Technology, Atlanta, Engineering Experiment Station, 1965).

${ }^{34}$ J. C. Mullins and W. T. Ziegler, "Phase equilibria in the argon-helium and argon-hydrogen systems from $68^{\circ}$ to $108^{\circ} \mathrm{K}$ and pressures to 120 atmoshperes," in Int. Adv. Cryo. Eng., Vol. 10 (Plenum Press, New York, 1965) pp. $171-181$.

${ }^{35}$ J. E. Sinor and F. Kurata, J. Chem. Eng. Data 11, 537-539 (1966).

${ }^{36}$ V. G. Skripka and N. N. Lobanova, "Phase and volume ratios at low temperatures and high pressures. Experimental study of solubility of helium and neon in liquid oxygen, nitrogen, and argon," Collection of papers Cryogenmash 13, 90-103 (1971).

${ }^{37}$ W. B. Streett, Trans. Faraday Soc. 65, 696 (1969).
${ }^{38}$ W. B. Streett and J. L. E. Hill, Trans. Faraday Soc. 67, 622 (1971).

${ }^{39} \mathrm{~W}$. B. Streett and A. L. Erickson, Phys. Earth Planet. Inter. 5, 357-366 (1972).

${ }^{40}$ A. L. Blancett, K. R. Hall, and F. B. Canfield, Physica 47, 75-91 (1970),

${ }^{41}$ B. E. Kanishev and L. L. Pitaevskaya, "Speed of sound and density of binary mixtures of helium with argon," Inzh.-Fiz. Zh. 39, 1090-1094 (1980).

${ }^{42}$ N. D. Kosov and I. S. Brovanov, "Compressibility of binary mixtures of helium, nitrogen, and argon with carbon dioxide from $59 \times 10^{5}$ to $590 \times$ $10^{5} \mathrm{~Pa}$," Teploenergetika , 77-79 (1975).

${ }^{43}$ V. Y. Maslennikova, V. A. Abovskii, A. N. Egorov, and D. S. Tsiklis, "Compressibility of homogeneous gaseous solutions under high pressures: helium-argon system,” Russ. J. Phys. Chem. A 52, 2968-2969 (1978).

${ }^{44}$ V. N. Popov, V. I. Chernyshev, and V. R. Petrov, "P-V-T-x dependence of helium-argon mixtures,” Moscow Energy Institute 75, 69-74 (1970).

${ }^{45}$ J. A. Provine and F. B. Canfield, Physica 52, 79-91 (1971).

${ }^{46}$ D. Vidal, L. Guengant, P. Malbrunot, and J. Vermesse, Physica A 137, 417-424 (1986).

${ }^{47}$ D. Vidal, P. Malbrunot, and J. Vermesse, Int. J. Thermophys. 12, 943-948 (1991).

${ }^{48}$ Y. Hanayama, "Measurements on adiabatic compressibility of mixed gases (He-Xe, He-Ar) under high pressure," Ehime Daigaku Kiyo, Dai-3-bu 9 23-31 (1978).

${ }^{49}$ Y. L. Kachanov, B. E. Kanishev, and L. L. Pitaevskaya, Inzh.-Fiz. Zh. 44, 5-8 (1983).

${ }^{50} \mathrm{~T}$. Nishitake and Y. Hanayama, "Measurements on adiabatic compressibility of helium-argon mixed gas under high pressure," Tech. Rep. 4 (Ehime University, 1977) section III, Volume 8, pp. 507-513.

${ }^{51}$ N. K. Kalfoglou and J. G. Miller, J. Phys. Chem. 71, 1256-1264 (1967).

${ }^{52}$ M. L. Martin, R. D. Trengove, K. R. Harris, and P. J. Dunlop, Aust. J. Chem. 35, 1525 (1982).

${ }^{53}$ C. C. Tanner and I. Masson, Proc. Royal Soc. A 126, 268-288 (1930).

${ }^{54}$ W. B. Streett, J. Chem. Phys. 42, 500-503 (1965).

${ }^{55}$ W. B. Streett, J. Chem. Phys. 46, 3282-3286 (1967).

${ }^{56}$ W. B. Streett and J. L. E. Hill, J. Chem. Phys. 54, 5088-5094 (1971).

${ }^{57}$ N. J. Trappeniers and J. A. Schouten, Physica 73, 539-545 (1974).

${ }^{58}$ E. V. Konovodchenko, V. V. Pashkov, and Y. I. Khokhlov, "Volumetric thermodynamic properties of Ne-Ar solutions," Ukr. Fiz. Zh. 26, 1480-1485 (1981).

${ }^{59}$ U. K. Deiters and T. Kraska, High-pressure fluid phase equilibria: phenomenology and computation, Vol. 2 (Elsevier, Amsterdam, 2012).

${ }^{60}$ A. Deerenberg, J. A. Schouten, and N. J. Trappeniers, Physica A 101, 459-476 (1980).

${ }^{61}$ E. Tiesinga, P. J. Mohr, D. B. Newell, and B. N. Taylor (2018), "The 2018 CODATA recommended values of the fundamental physical constants" (Web Version 8.1). Database developed by J. Baker, M. Douma, and S. Kotochigova. Available at http://physics.nist.gov/constants, National Institute of Standards and Technology, Gaithersburg, MD 20899.

${ }^{62}$ I. H. Bell and U. K. Deiters, AIChE 64, 2745-2757 (2018). 


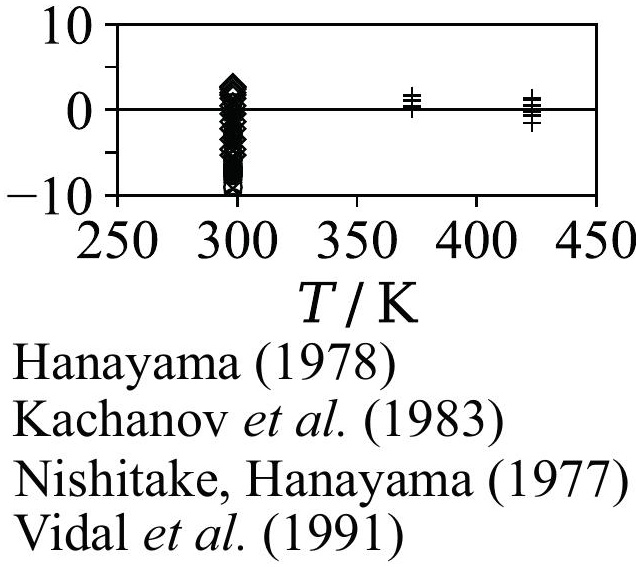




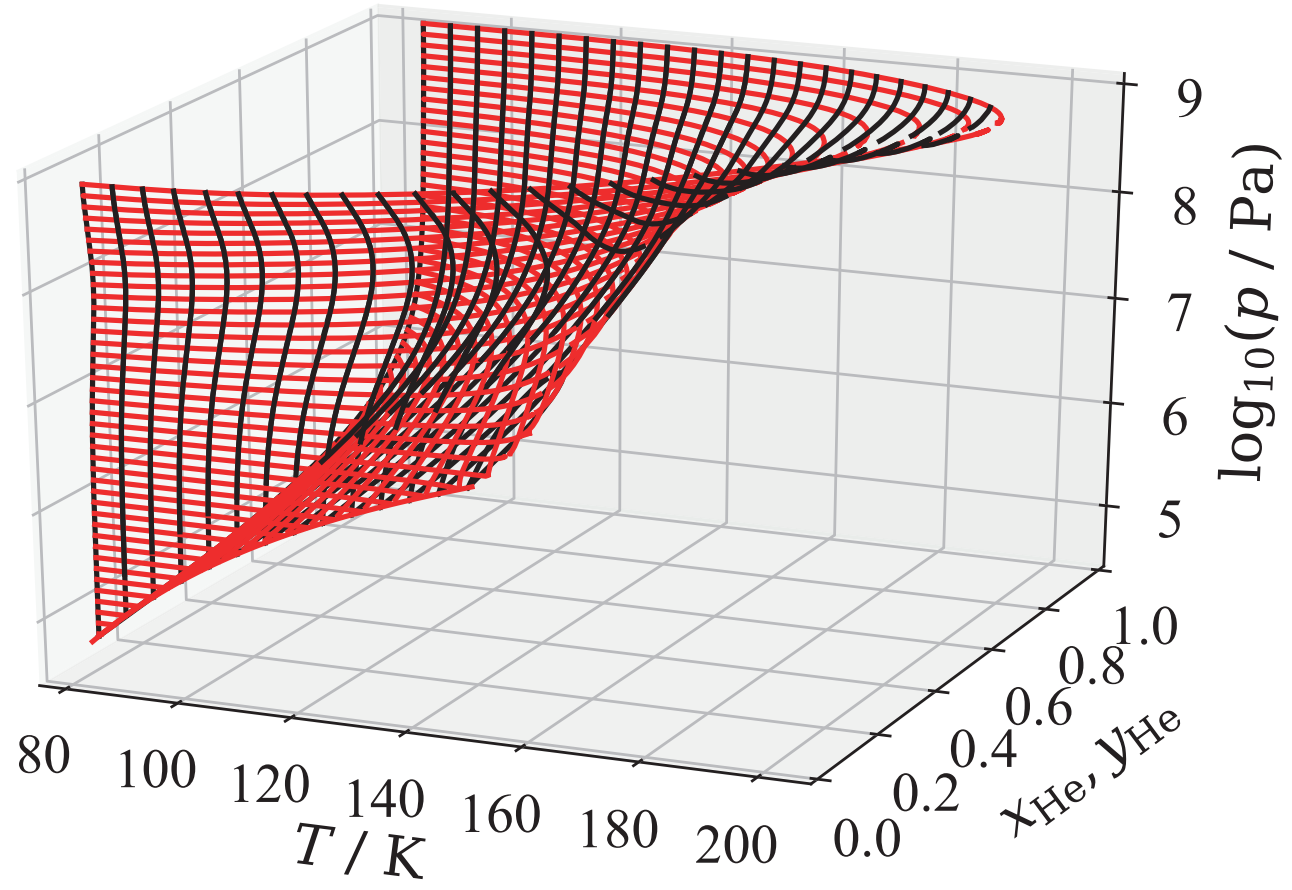


$30-41 \mathrm{~K}$
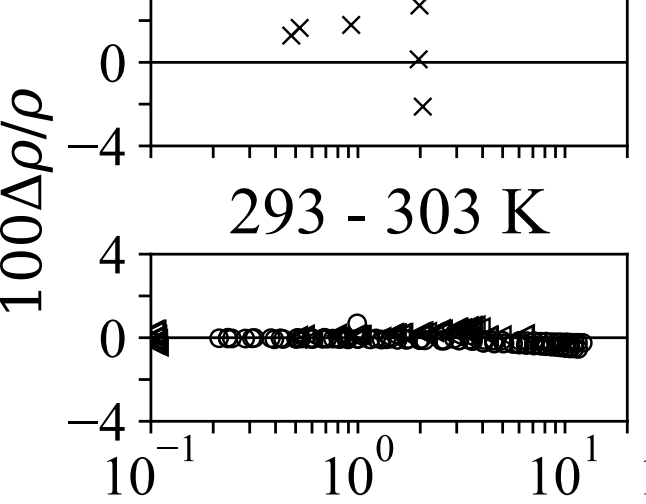

$233 \mathrm{~K}$

$273 \mathrm{~K}$

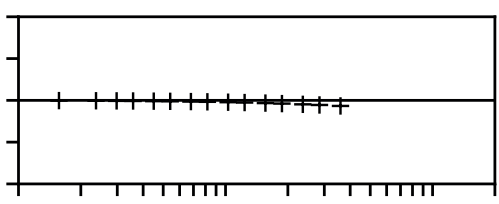

$313 \mathrm{~K}$

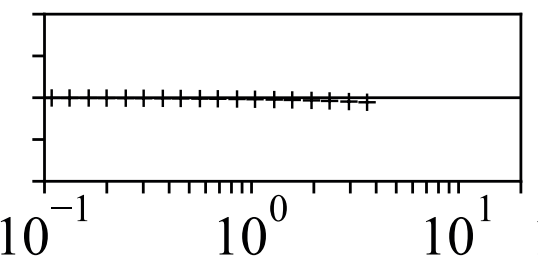

$p / \mathrm{MPa}$ $\diamond$ Holborn, Otto (1924)

- Kestin et al. (1981)

× Richardson, Leachman (unpub.)
+ Vogl, Hall (1972)

$\triangleleft$ Kestin, Nagashima (1964) 


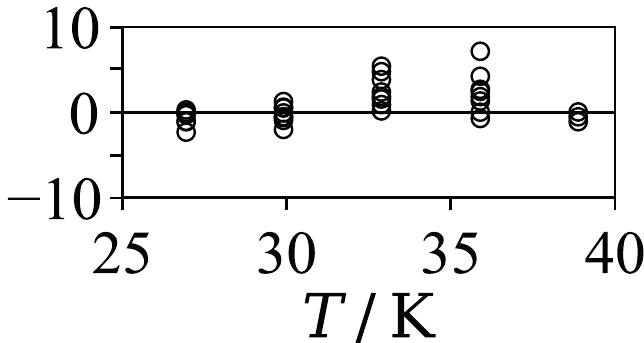




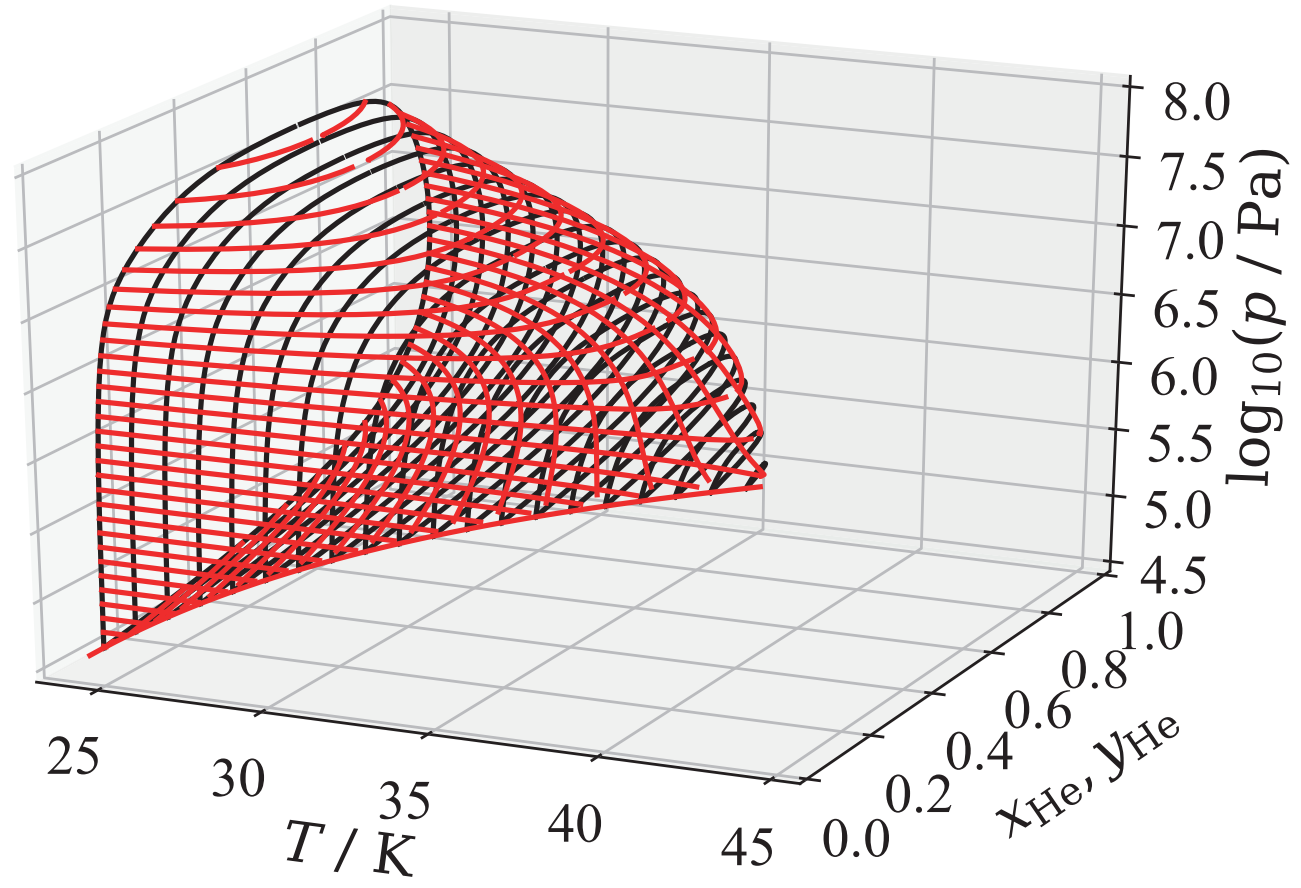




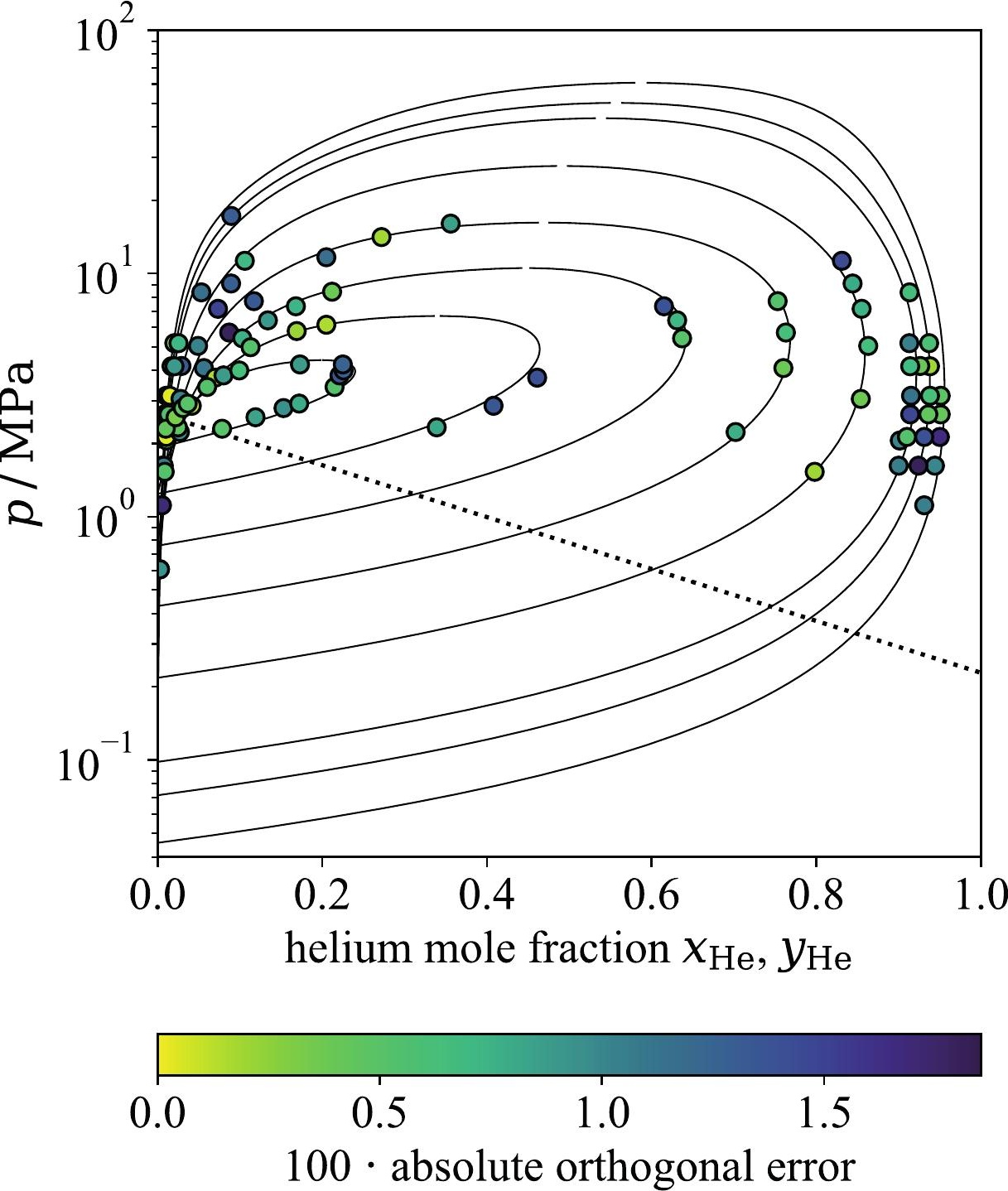




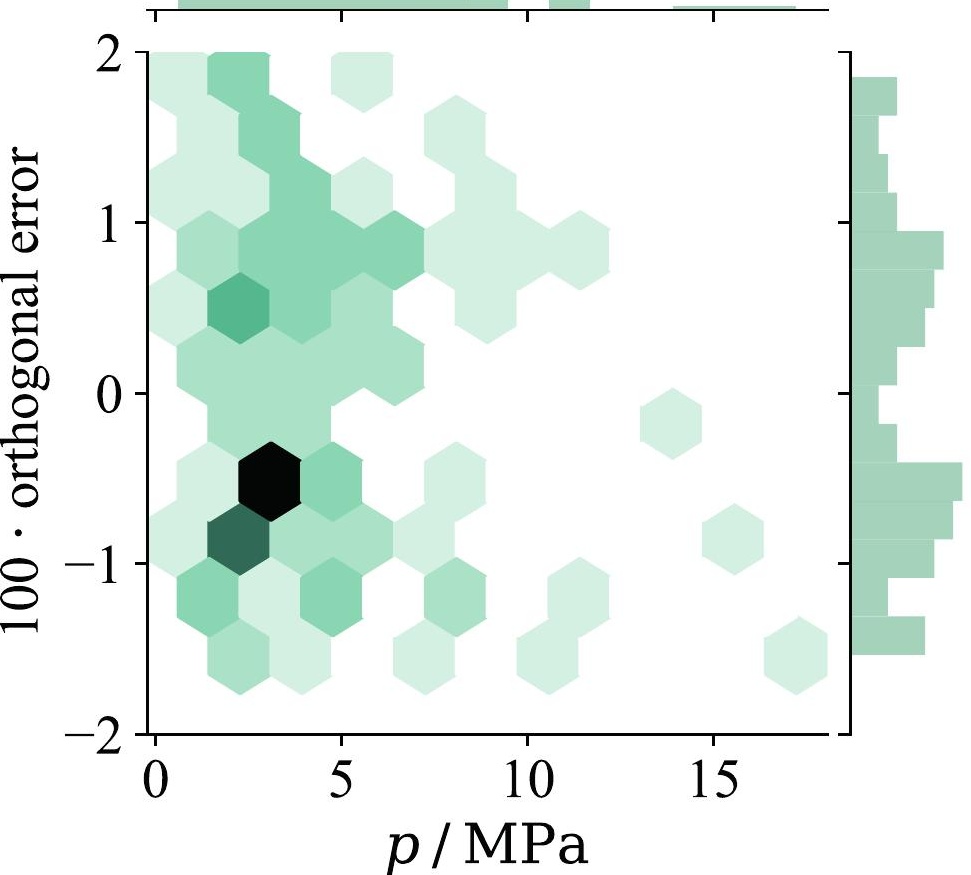


$102 \mathrm{~K} \quad 111 \mathrm{~K}$

\begin{tabular}{l}
$\frac{0}{2}$ \\
$\frac{a}{2}$ \\
\hdashline \\
-1
\end{tabular}
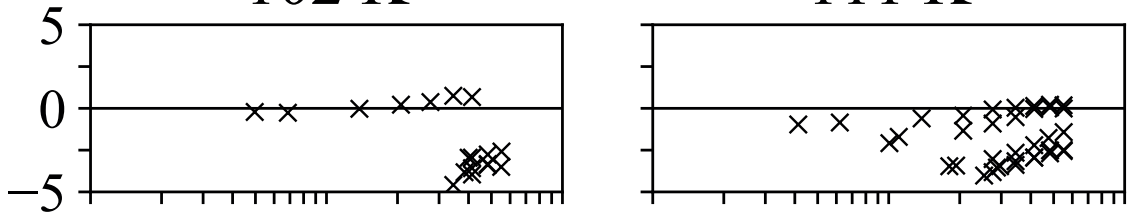

$121 \mathrm{~K}$

$298 \mathrm{~K}$

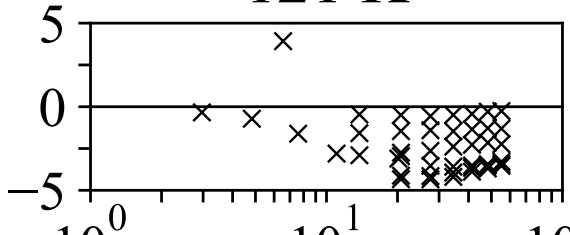

$10^{2} 10^{0} \quad 10^{1}$

$p / \mathrm{MPa}$

- Kestin et al. (1981) + Vidal et al. (1991)

$\times$ Streett (1967) $\quad \diamond \quad$ Vidal et al. (1986) 


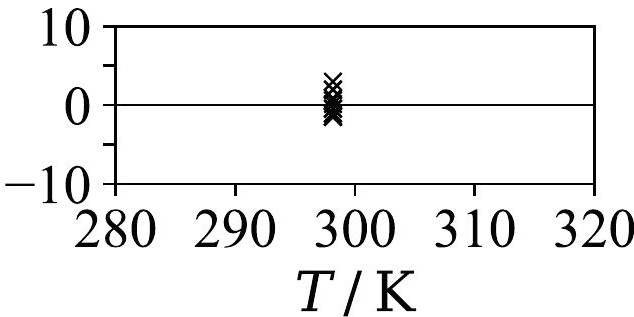




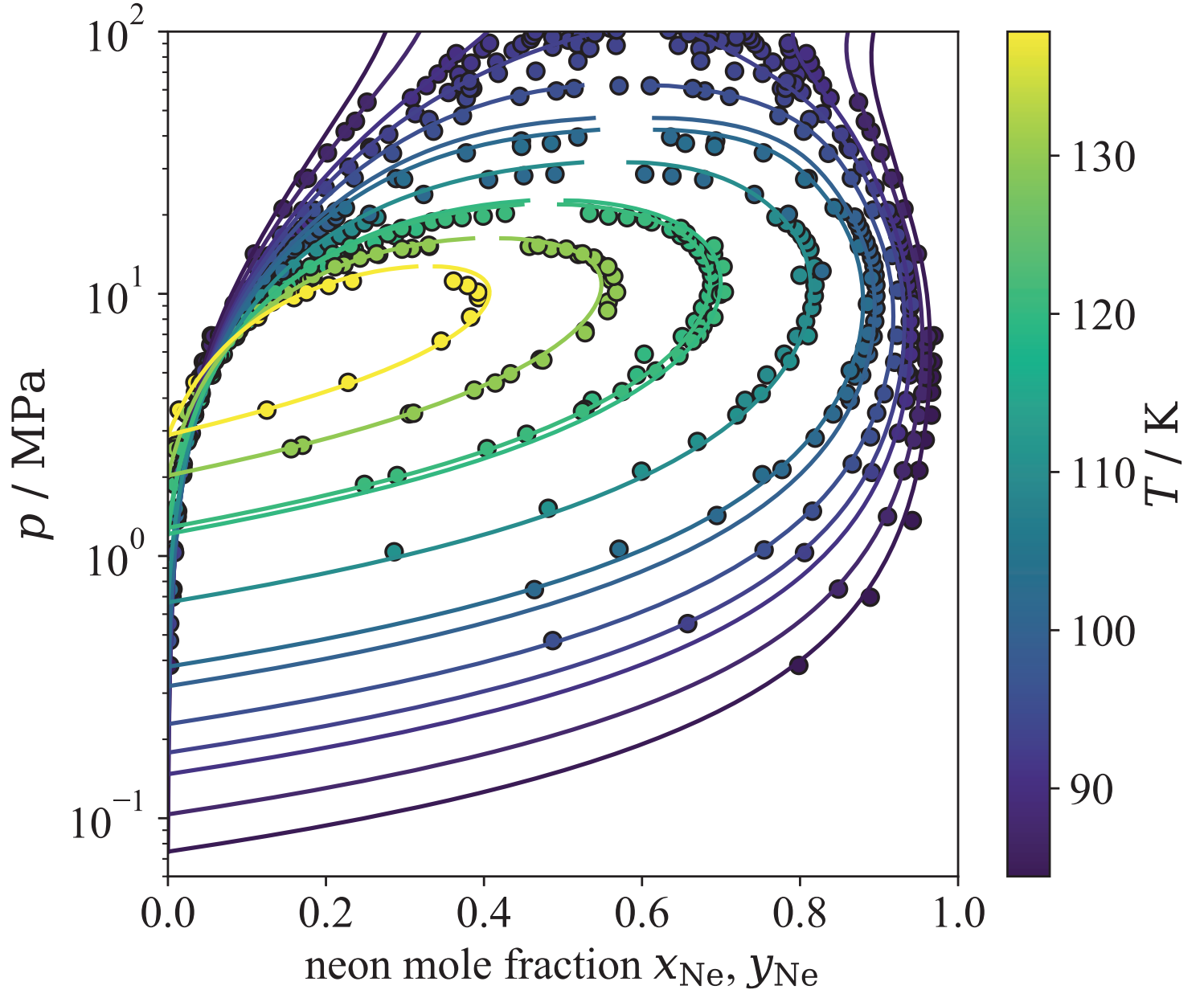




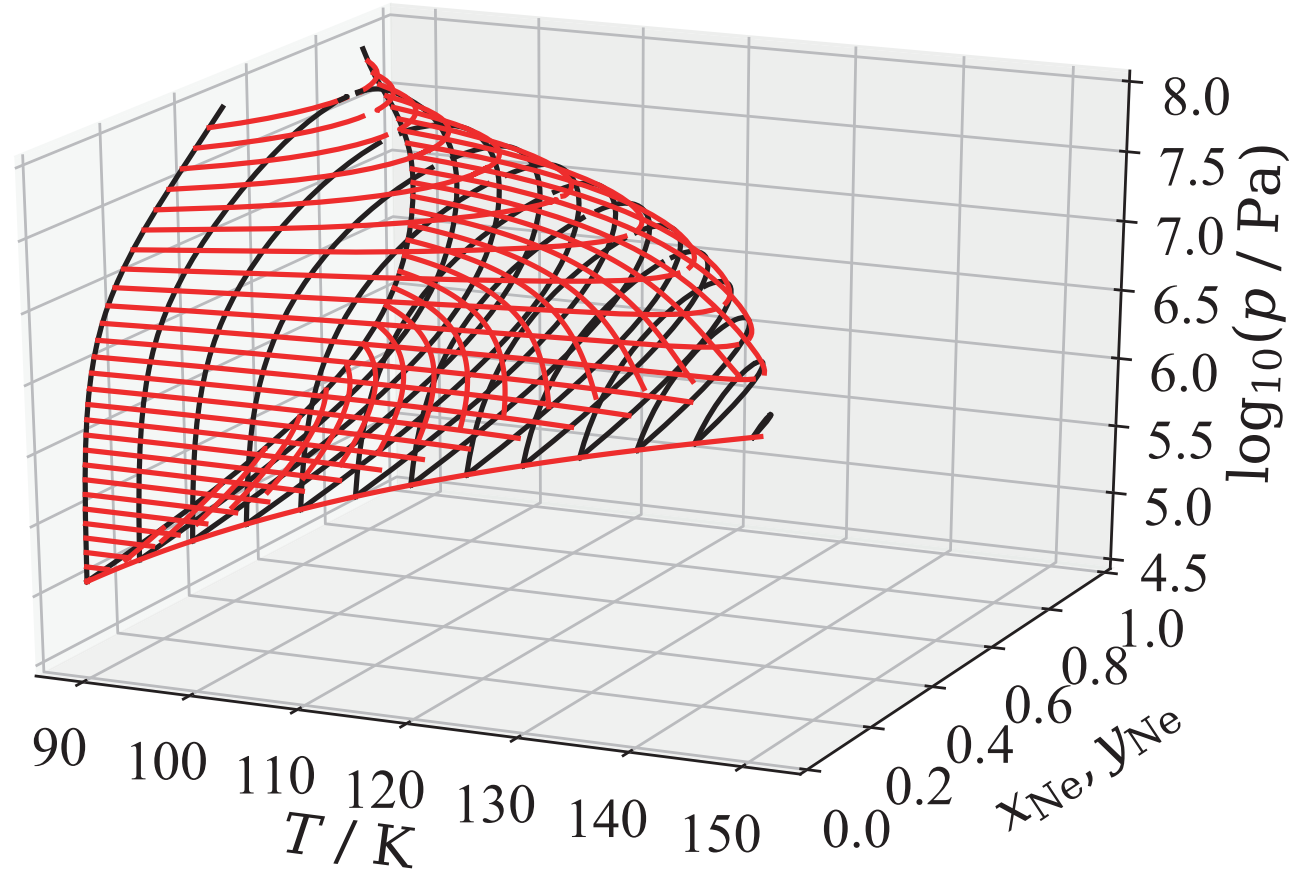




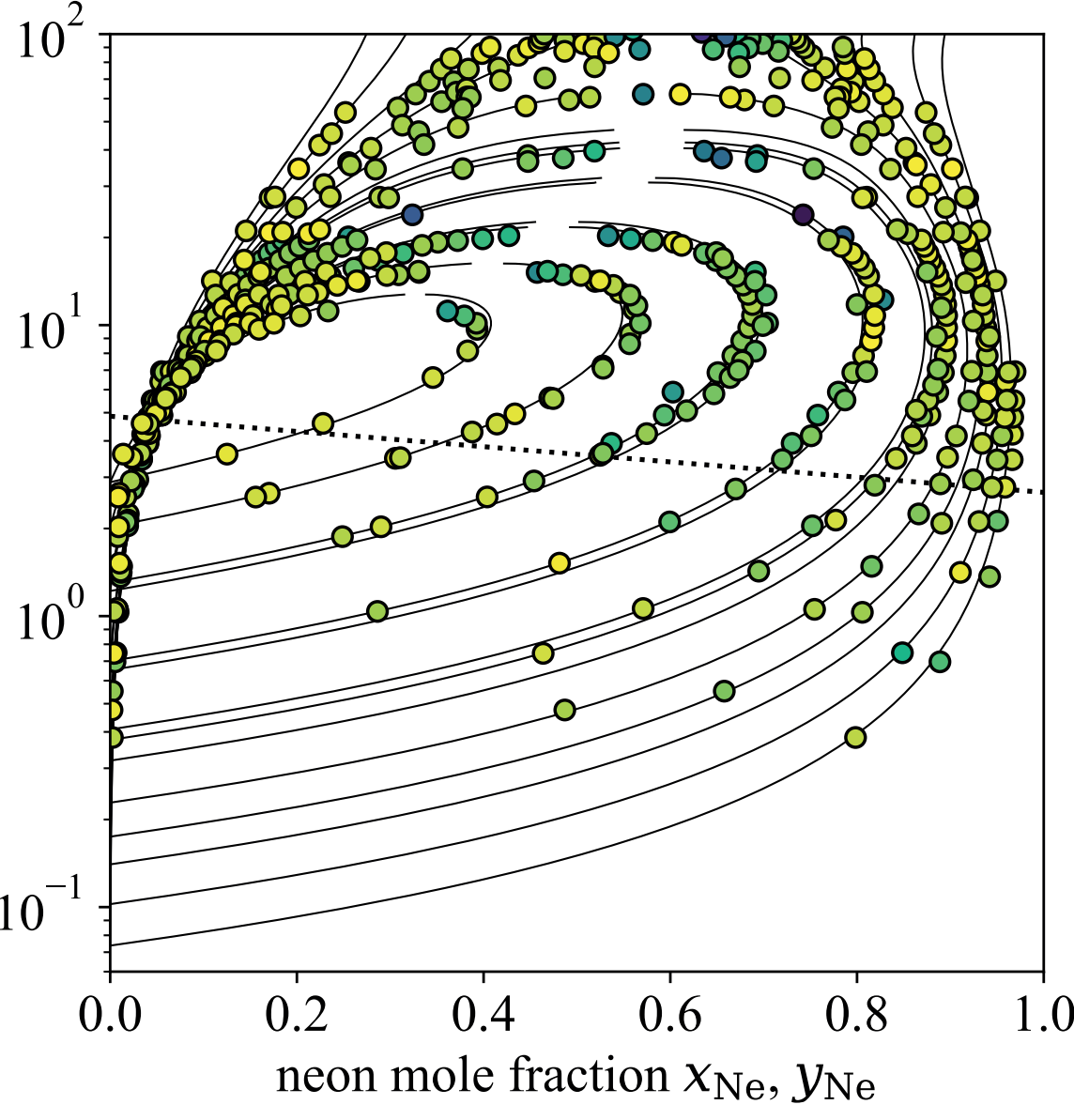




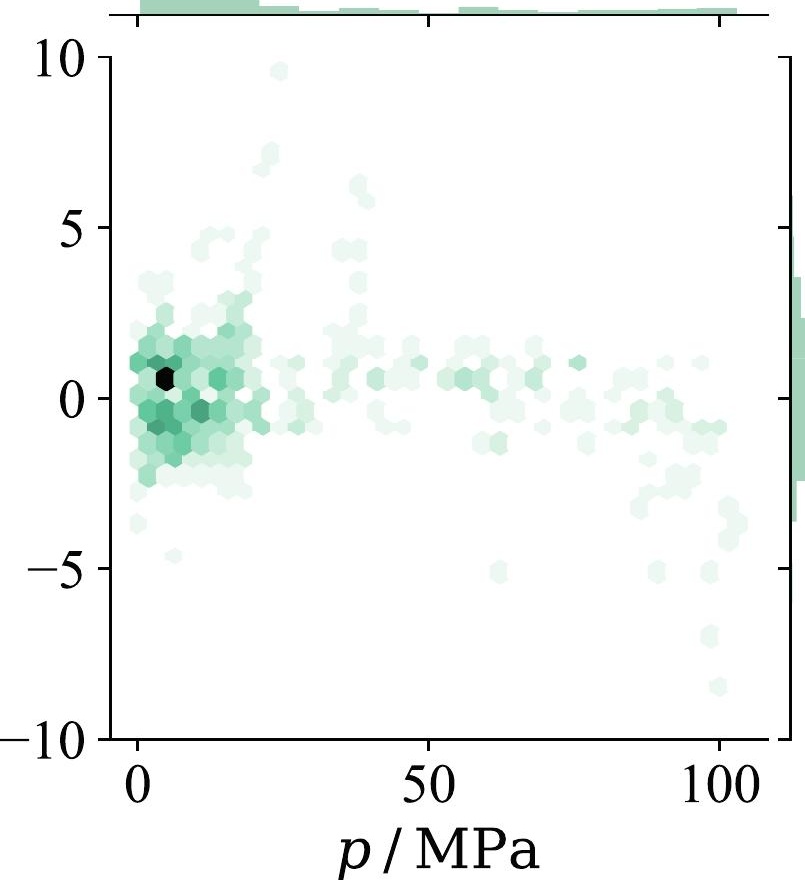




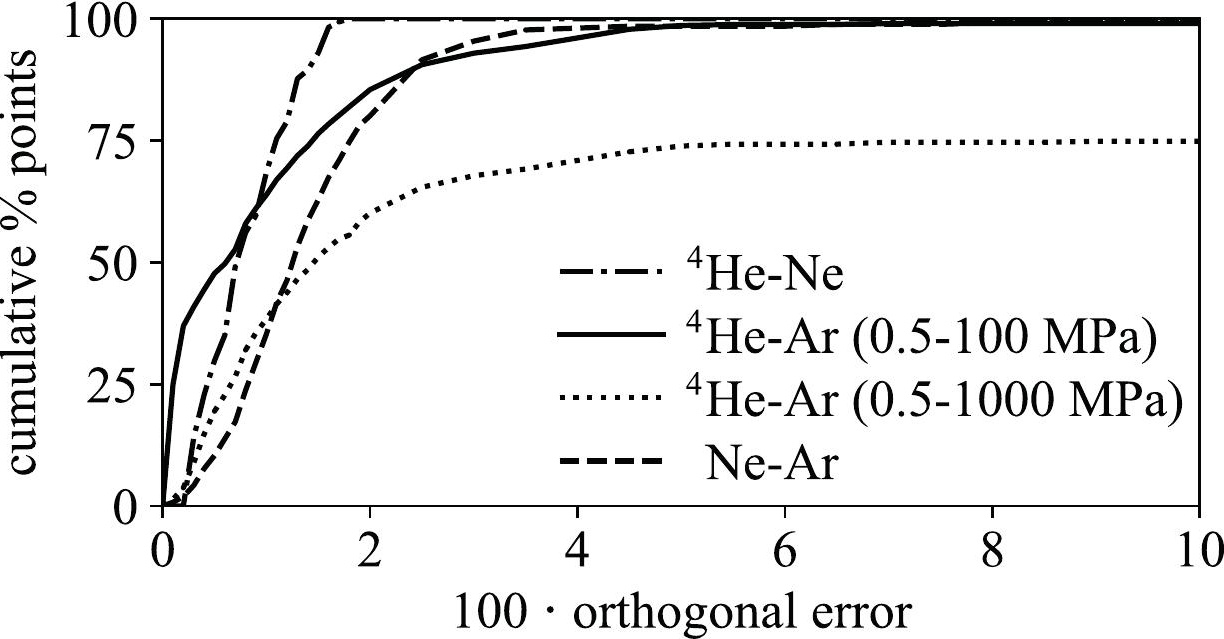

